\title{
Experimental studies of trace element partitioning in Ca,Al-rich compositions: Anorthite and perovskite
}

\author{
S. B. Simon, ${ }^{1}$ S. M. Kuehner, ${ }^{1}$ A. M. Davis, ${ }^{2}$ L. Grossman, ${ }^{1,2}$ M. L. Johnson, ${ }^{3}$ and D. S. BurnetT ${ }^{3}$ \\ ${ }^{1}$ Department of the Geophysical Sciences, University of Chicago, Chicago, IL 60637, USA \\ ${ }^{2}$ Enrico Fermi Institute, University of Chicago, Chicago, IL 60637, USA \\ ${ }^{3}$ Division of Geological and Planetary Sciences, California Institute of Technology, Pasadena, CA 91125, USA
}

(Received March 12, 1993; accepted in revised form November 5, 1993)

\begin{abstract}
Using electron probe and ion probe techniques, experimental crystal-liquid partition coefficients $(D)$ have been measured in meteoritic Ca,Al-rich inclusion (CAI) compositions for $\mathrm{Mg}, \mathrm{Zr}, \mathrm{Y}$, and REEs in anorthite and perovskite. Partitioning data for $\mathrm{Ti}$ in anorthite and $\mathrm{Al}$ in perovskite are also reported. Where cross-comparisons are possible between electron and ion probe data, agreement is good. Concentration variations in anorthite for many elements are beyond what can be explained by fractional crystallization, but show well-defined interelement correlations which could reflect the temperature dependence of the $D$ values or could result from liquid boundary layers. For anorthite our $D$ values for REEs are lower, and they decrease more rapidly with decreasing ionic radius than most in the literature. Most of the older REE $D$ patterns for plagioclase in the literature are too flat because of insufficient purity of mineral separates or because of analytical problems. New ion probe data for minor and trace elements in anorthite from type B CAIs permit detailed comparisons with fractional crystallization models based on the measured $D$ values. For most comparisons, models and observations do not agree for amounts of crystallization less than $90 \%$. It is possible that anorthite does not appear until after $95 \%$ crystallization, compared to about $40 \%$ which would be expected from isothermal equilibrium crystallization experiments. The LREEs are highly compatible elements in perovskite, but $D$ values drop sharply for the HREEs, Y, and $\mathrm{Zr} . D$ values for REEs increase strongly from air to highly reducing conditions as coupled REE-Ti ${ }^{+3}$ substitutions become possible. Model calculations show that REE patterns in igneous perovskites from CAIs will reflect the $D$ pattern, and the models can explain some REE patterns from compact type A CAIs. However, there are other sets of trace element data for perovskite in CAIs that cannot easily be explained by igneous processes.
\end{abstract}

\section{INTRODUCTION}

IN ADDITION TO THEIR IMPORTANCE as high-temperature materials from the solar nebula, the igneous (type B), coarsegrained, Ca,Al-rich inclusions (CAIs) (e.g., GroSSMAN, 1980 ) offer a unique opportunity to study the distribution of minor and trace elements in an intact magmatic system which underwent fractional crystallization from a single starting liquid of known bulk composition, crystallization sequence (STOLPER, 1982), and approximately known cooling rate (MACPHERSON et al., 1984; STOLPER and PAQUE, 1986). Ion microprobe techniques provide the analytical data to exploit this opportunity. Crystal-liquid partition coefficients ( $D$ values) are also required. These are available for melilite (BECKETT et al., 1990; KUEHNER et al., 1989). The $D$ values required to match measured refractory lithophile element trends in type B fassaite have been calculated by SIMON et al. (1991). This work provides $D$ values for anorthite and perovskite, and compares crystallization model predictions with analyses of CAI phases. A considerable literature exists on partitioning of REEs in plagioclase; however, reported $D$ values for a given REE vary by over two orders of magnitude. The $D$ values at the higher end of this range would indicate that CAI anorthite is a significant host phase for at least the LREEs. Thus, direct measurements of anorthite $D$ values from CAI liquids are warranted.

Understanding the igneous behavior of lithophile trace elements in CAI compositions is also important because it is likely that there are features in the trace element microdistributions which cannot be explained by igneous processes and which, for example, may indicate the nature of relict phases (MURRELl and BURNETT, 1987; WoOlum et al., 1988; JOHNSON et al., 1988; BURNETT et al., 1990; SIMON et al., 1991; KENNEDY et al., 1991). Knowledge of perovskite $D$ values can aid in distinguishing relict grains from equilibrium crystals for a given inclusion.

Using combined electron and ion probe techniques, we have measured $D$ values for $\mathrm{Sr}, \mathrm{Y}, \mathrm{Zr}, \mathrm{La}, \mathrm{Sm}$, and $\mathrm{Yb}$ in anorthite and perovskite. We also measured $\mathrm{Mg}$ and $\mathrm{Ti}$ in anorthite, as well as $\mathrm{Mg}, \mathrm{Al}$, and $\mathrm{Si}$ in perovskite. Ion probe analyses of anorthite in CAIs were carried out for comparison. Magnesium partitioning in anorthite is of special significance because much of the magnesium isotopic data reported from CAIs has been obtained on this phase.

\section{EXPERIMENTAL}

Anorthite is a late-crystallizing phase in CAI compositions, appearing after spinel, melilite, and either before or after clinopyroxene, depending on bulk composition and cooling rate (STOLPER and PAQUE, 1986). Our 224 bulk composition is based on the late stage liquid composition of STOLPER and PAQUE ( 1986), experiment 224, modified to enhance the fassaitic pyroxene component. Our expectation was that pyroxene would be the liquidus phase, but large $(\geq 100$ $\mu$ ) euhedral crystals of anorthite appeared instead. The QPX composition was prepared as a fassaite glass standard for ion probe analysis, based on a Ti-rich fassaite composition from BECKLTT (1986). Pe- 
Table 1. Electron microprobe analyses of starting materials.

\begin{tabular}{|c|c|c|c|c|c|c|}
\hline & \multicolumn{3}{|c|}{ ـــ" $224 "$} & \multicolumn{3}{|c|}{$-\mathrm{OPX}-$} \\
\hline & $\begin{array}{c}\text { Oxide } \\
\text { wt\% }\end{array}$ & $\begin{array}{l}\sigma_{0}{ }^{*} \\
(\%)\end{array}$ & $\sigma_{0} / \sigma_{c}{ }^{*}$ & $\begin{array}{c}\text { Oxide } \\
w t \%\end{array}$ & $\begin{array}{l}\sigma_{0}{ }^{*} \\
(\%)\end{array}$ & $\sigma_{\mathrm{d}} / \sigma_{\mathrm{c}}^{*}$ \\
\hline $\mathrm{MgO}$ & 4.00 & 0.8 & 1.1 & 8.24 & 0.7 & 1.4 \\
\hline $\mathrm{Al}_{2} \mathrm{O}_{3}$ & 18.8 & 0.5 & 1.1 & 17.2 & 0.4 & 0.8 \\
\hline $\mathrm{SiO}_{2}$ & 42.3 & 0.6 & 2.1 & 29.9 & 0.3 & 0.9 \\
\hline $\mathrm{CaO}$ & 27.0 & 0.5 & 1.2 & 24.7 & 0.4 & 1.1 \\
\hline $\mathrm{TiO}_{2}$ & 1.76 & 3.1 & 1.2 & 14.4 & 0.8 & 0.9 \\
\hline $\mathrm{SrO}$ & 0.720 & 1.6 & 2.0 & 0.743 & 0.8 & 1.0 \\
\hline $\mathrm{Y}_{2} \mathrm{O}_{3}$ & 0.368 & 2.1 & 1.3 & 0.386 & 1.6 & 1,0 \\
\hline $\mathrm{ZrO}_{2}$ & 1.32 & 2.0 & 2.9 & 1.33 & 0.9 & 1.3 \\
\hline $\mathrm{La}_{2} \mathrm{O}_{3}$ & 1.02 & 1.0 & 1.0 & 1.05 & 0.7 & 1.0 \\
\hline $\mathrm{Sm}_{2} \mathrm{O}_{3}$ & 1.02 & 0.7 & 1.3 & 1.03 & 0.6 & 1.3 \\
\hline $\mathrm{Yb}_{2} \mathrm{O}_{3}$ & 0.969 & 0.6 & 2.0 & 0.977 & 0.3 & 1.1 \\
\hline Sum & 99.2 & 0.2 & & 99.9 & 0.2 & \\
\hline
\end{tabular}

${ }^{*} \sigma_{0}=$ observed relative standard deviation of 10 analyses; $\sigma_{c}$ $=$ counting statistics relative standard deviation; values of $\sigma_{\alpha} / \sigma_{c}$ less than 2 indicate that starting materials are acceptably homogeneous.

rovskite was observed to be the liquidus phase, presenting an opportunity for the measurement of perovskite $D$ values.

The starting materials were made from reagents: $\mathrm{SiO}_{2}, \mathrm{Al}_{2} \mathrm{O}_{3}, \mathrm{MgO}$, $\mathrm{TiO}_{2}$, and $\mathrm{CaCO}_{3}$. The oxides were dried overnight in mullite crucibles at $800^{\circ} \mathrm{C}$, and the carbonate dried overnight at $140^{\circ} \mathrm{C}$. Weighed amounts were put in an agate mortar and ground for $5 \mathrm{~h}$ under reagent ethanol. The samples were allowed to dry, then decarbonated by heating at $200^{\circ} \mathrm{C}$ per h to $1000^{\circ} \mathrm{C}$, where they were kept $24 \mathrm{~h}$. Splits of approximately $300 \mathrm{mg}$ were weighed into Pt tubes, spiked with $0.03 \mathrm{cc}$ of a trace element solution made from reagent $\mathrm{SrCO}_{3}$, $\mathrm{Y}_{2} \mathrm{O}_{3}, \mathrm{La}_{2} \mathrm{O}_{3}, \mathrm{Sm}_{2} \mathrm{O}_{3}, \mathrm{Yb}_{2} \mathrm{O}_{3}$, and $\mathrm{Zr}\left(\mathrm{NO}_{3}\right)_{4}$, degassed in an open tube at $1100^{\circ} \mathrm{C}$, fused in a closed tube at $13622^{\circ} \mathrm{C}$, and ground in an agate ball mill. The final three steps were then repeated.

Electron microprobe analyses of superliquidus quench samples are given in Table 1 .

Most crystallization experiments were run with $10-30 \mathrm{mg}$ powder glued with polyvinyl alcohol to $\mathrm{Pt}$ wire loops and left to dry overnight. Crystals were grown by fractional crystallization during slow cooling. Short isothermal experiments were used to define the conditions for the slow cooling experiments. Platinum loop experiments were run in air and quenched in water. The QPX-9 experiment was performed at an oxygen fugacity $\left(f_{\mathrm{O}_{2}}\right)$ of $10^{-17}$ atm at $1375^{\circ} \mathrm{C}$ using a graphite crucible in pure CO. Run conditions are summarized in Table 2.

Electron microprobe analytical conditions were optimized for mi- nor element analyses, using the procedures given by KULHNER $\mathrm{ct}$ al. (1989). Very low detection limits were obtained; nevertheless, the electron probe analyses for $\mathrm{Sm}_{2} \mathrm{O}_{3}$ and $\mathrm{Yb}_{2} \mathrm{O}_{3}$ in anorthite, nominally 100-250 ppm (at 1-3 times detection limits for individual analyses), appear to be high by factors of 2-10 compared to ion probe measurements, and have been rejected. However, ion and electron probe measurements for $\mathrm{La}_{2} \mathrm{O}_{3}$ at 200-500 ppm are consistent (see below). By comparison with the overall data set for incompatible elements, the high electron probe analyses for $\mathrm{Sm}$ and $\mathrm{Yb}$ cannot be explained by beam scattering or polishing contamination but could reflect continuum secondary fluorescence or systematic errors in background subtraction given the very low peak to background ratios for these measurements.

Ion microprobe analyses were made using a modified AEI IM-20 instrument at the University of Chicago. Techniques are described by HINTON et al. (1988) and DAvis et al. (1991). Ion yields [(secondary ion counting rate)/(unit concentration)(primary ion current )] were measured using a variety of synthetic and natural minerals and glasses. Ion yields for REEs were measured using the same synthetic glasses (DRAKE and WEILL, 1972) commonly used as standards for electron microprobe analysis. Previous experience has shown that the ion yield for $\mathrm{Si}^{+}$relative to $\mathrm{Ca}^{+}$varies from 0.38 to 0.52 among common silicate minerals for the energy filtering conditions used. Thus, the ion yicld for $\mathrm{Si}$ was adjusted for cach analysis such that the $\mathrm{SiO}_{2}$ contents by ion and electron microprobe agreed. Ion yields for other elements studied here are much less sensitive to matrix effects, so the same ion yields are used for all silicate materials. Each spot was analyzed after burning in with the primary ion beam for 2 min, then collecting data at each mass peak sequentially. For each spot, six cycles through the mass spectrum were made. For each cycle, the count rate at each mass was plotted as a function of time to ensure that the beam remained on a single phase without passing through a boundary or through a tiny inclusion.

\section{RESULTS}

\section{Overview of the Anorthite Experiments}

Sample 224-8 contains large (hundreds of microns) anorthite crystals, plus glass. Samples 224-9 and 224-10, which were cooled to lower temperatures than 224-8 (Table 2), contain åkermanitic melilite $(\AA \mathrm{k} 70-\AA \mathrm{k} 80)$ in addition to anorthite. The 224-9 and 224-10 samples are much more complex and are not considered in any detail. The anorthite in 224-8 is about An97 because of a small amount of $\mathrm{Na}$ contamination of unknown origin.

Table 2. Run histories.

\begin{tabular}{|c|c|c|c|c|c|c|c|}
\hline Run & $\begin{array}{l}\mathrm{T}_{\mathrm{i}}^{*} \\
{ }^{\circ} \mathrm{C}\end{array}$ & $\begin{array}{c}\mathrm{t}_{\mathrm{i}}^{\dagger} \\
\mathrm{h}\end{array}$ & $\begin{array}{l}\text { Slope } \\
{ }^{\circ} \mathrm{C} / \mathrm{hr}\end{array}$ & $\begin{array}{l}\mathrm{T}_{\mathbf{f}}^{\ddagger} \\
{ }^{\circ} \mathrm{C}\end{array}$ & $\begin{array}{c}t_{f} \$ \\
h\end{array}$ & $f_{\mathrm{O}_{2}}$ & Results \\
\hline 224-1 & 1165 & 1 & - & - & - & air & an + glass + mel? \\
\hline $224-2$ & 1184 & 1 & - & - & - & air & an + glass \\
\hline $224-3$ & 1205 & 1 & - & - & - & air & an + glass \\
\hline $224-4$ & 1228 & 1 & - & - & - & air & an + glass \\
\hline $224-5$ & 1282 & 1 & - & - & - & air & trace an + glass + quench $x$ tals \\
\hline $224-6$ & 1332 & 1 & - & & - & air & trace an + glass \\
\hline $224-7$ & 1351 & 1 & - & - & - & air & glass \\
\hline $224-8$ & 1351 & 2 & 6 & 1205 & 0 & air & an + glass \\
\hline $224-9$ & 1362 & 2.5 & 12 & 1148 & 0 & air & $a n+$ glass $+\mathrm{mel}^{\circ}$ \\
\hline $224-10$ & 1359 & 2 & 12 & 1104 & 0 & air & an + glass + mel $^{\text {In }}$ \\
\hline QPX 2 & 1362 & 1 & - & - & - & air & glass \\
\hline QPX 8 & 1375 & 2 & 2.2 & 1335 & 1.25 & air & $p v+$ glass \\
\hline QPX 9 & 1375 & 2 & 2.2 & 1335 & 4 & $\mathrm{C}-\mathrm{CO}$ & pv + black glass + quench (?) pyx \\
\hline
\end{tabular}

*Initial temperature $\ddagger$ Time held at initial temperature. $\ddagger$ Final temperature. §Time held at final temperature. $I_{a n}=$ anorthite; $m e l=$ melilite; $p y x=$ pyroxene; pv $=$ perovskite. $0_{\sim} 30 \%$ an; $\sim 10 \%$ Åk-rich mel. ${ }_{\sim} 40 \%$ an, $\sim 15 \%$ Ăk-rich mel 


\section{Glass Compositions}

Only small deviations from homogeneity are observed in the 224-8 glass ( Table 3 ). No systematic differences in composition were found between points near crystals and those far from crystals. In contrast, the faster cooling rate and greater degree of crystallization of the 224-9 and 224-10 samples (Table 2) resulted in liquids at the time of quench which were heterogeneous, especially in 224-10. The variations in composition reflect varying amounts of plagioclase and åkermanite removal from the starting composition for a given volume of liquid.

Comparison of the electron probe data for 224-8 and starting glass compositions yields $20.6 \pm 0.8 \%$ anorthite crystallization where the uncertainty represents the sample standard deviation for nine elements (all except $\mathrm{Si}$ and $\mathrm{Sr}$ ).

\section{Comparison of Electron and Ion Probe Analyses}

The 224-8 data permit comparisons between electron and ion probe analysis. Defining $\Delta$ as the percent difference between the electron and ion probe analyses for a given element, the values given in Table 3 show quite satisfactory agreement for the 224-8 glass, with both positive and negative differences being equally probable and with the largest difference $(\mathrm{Zr})$ being $+11 \%$. Composition variations for the minor elements in 224-8 anorthite (discussed below) complicate comparisons, but the same crystals were analyzed by both techniques, and comparisons of average concentrations give reasonable agreement (last column, Table 3 ). The largest differences are for $\mathrm{Sr}(+12 \%)$ and $\mathrm{Ti}(-10 \%)$. Elcctron probe data at concentration levels greater than about $0.1 \%$ are widely accepted as accurate; consequently, electron probe analyses serve as the point of reference. However, at lower concentration levels, e.g., for $\mathrm{Ti}$ and $\mathrm{La}$ in anorthite, the precision of the electron probe analyses is probably a factor in the observed differences between the two instruments.

\section{Anorthite Partitioning}

\section{Variations due to fractional crystallization}

The large counting statistics errors on the electron probe data prohibit strong conclusions, but the precise ion probe data show that the variations of $\mathrm{Ti}, \mathrm{Y}, \mathrm{Zr}$, and the REEs are far beyond those expected for fractional crystallization. Variations in $\mathrm{Mg}$ are much smaller, only discernable in the ion probe data. For a $D$ of 1.2 (our maximum estimate; see below), the observed variations in $\mathrm{Sr}$ (4-5\% s.d.), although small in absolute terms, are larger than expected $(1 \%)$. The observed variations indicate either that $D$ values varied during crystallization, due to temperature or liquid composition variations, or that interface equilibrium was not always maintained.

\section{Interelement correlations}

In Fig. 1 b,c $\mathrm{Mg}$ and $\mathrm{Sr}$ vary by less than $20 \%$, whereas the REEs and $\mathrm{Zr}$ vary by over a factor of 2 . The overall ranges are similar for the ion and electron probe data. The ion probe data are not affected by micron-sized or larger glass inclusions, as all counting rates for the $224-8$ analyses remained uniform while the primary ion beam sputtered into the sample.

Variations in $\mathrm{La}, \mathrm{Sm}, \mathrm{Yb}, \mathrm{Y}$, and $\mathrm{Zr}$ in anorthite are larger than expected for fractional crystallization with constant $D$ values but, as illustrated for $\mathrm{Zr}$ and $\mathrm{La}$ in Fig. 1a, concentration variations for all these elements are linearly correlated. These linear relationships could be due to disequilibrium, representing varying degrees of enrichment in boundary layers but without fractionation. Alternatively, even with interface equilibrium, smooth (but not necessarily linear) interelement correlations could result because of changes in $D$ values at the different growth temperatures for the various points analyzed. If the relative $D$ values for different elements were independent of temperature, linear correlations would be produced. Regardless, for either interpretation, the data define precise, constant relative $D$ values: $D(\mathrm{Sm}) / D(\mathrm{La})=0.304$

Table 3. Comparison of electron microprobe (EP) and ion microprobe (IP) analyses of sample 224-8.

\begin{tabular}{|c|c|c|c|c|c|c|c|c|c|c|c|c|c|c|}
\hline & \multicolumn{7}{|c|}{-Glass } & \multicolumn{7}{|c|}{ Anorthite- } \\
\hline & $\begin{array}{c}\text { EP } \\
\text { Avg } \\
(w t \%)\end{array}$ & $\begin{array}{l}\sigma_{0}{ }^{*} \\
\mathrm{EP} \\
(\%)\end{array}$ & $\begin{array}{c}\sigma_{\alpha} / \sigma_{c}{ }^{*} \\
\mathrm{EP}\end{array}$ & $\begin{array}{c}\mathrm{IP}^{\dagger} \\
\text { Avg } \\
(\mathrm{w} t \%)\end{array}$ & $\begin{array}{c}\sigma_{0}{ }^{*} \\
\text { IP } \\
(\%)\end{array}$ & $\begin{array}{c}\sigma_{0} / \sigma_{c}{ }^{*} \\
\operatorname{IP}\end{array}$ & $\begin{array}{c}\Delta^{\ddagger} \\
(\%)\end{array}$ & $\begin{array}{c}\mathrm{EP} \\
\mathrm{Avg} \\
(\mathrm{wt} \%)\end{array}$ & $\begin{array}{c}\sigma_{0}{ }^{*} \\
\mathrm{EP} \\
(\%)\end{array}$ & $\begin{array}{c}\sigma_{\alpha} / \sigma_{c}{ }^{*} \\
E P\end{array}$ & $\begin{array}{c}\text { IP } \\
\text { Avg } \\
\text { (wt\%) }\end{array}$ & $\begin{array}{c}\sigma_{0}^{*} \\
\mathbb{P} \\
(\%)\end{array}$ & $\begin{array}{c}\sigma_{0} / \sigma_{c}{ }^{*} \\
\operatorname{PP}\end{array}$ & $\begin{array}{c}\wedge \ddagger \\
(\%)\end{array}$ \\
\hline $\mathrm{MgO}$ & 4.91 & 1.2 & 1.8 & 4.62 & 0.6 & 3.3 & +6.2 & 0.163 & 4.6 & 0.8 & 0.159 & 3.8 & 4.2 & +2.1 \\
\hline $\mathrm{Al}_{2} \mathrm{O}_{3}$ & 14.3 & 1.2 & 2.3 & 14.3 & 0.3 & 3.1 & +0.4 & 36.0 & 0.4 & 1.4 & 36.3 & 0.4 & 6.7 & -0.9 \\
\hline $\mathrm{SiO}_{2}$ & 42.2 & 1.4 & 4.7 & $\equiv 42.2$ & & & $\equiv 0.0$ & 44.5 & 0.5 & 1.7 & $=44.5$ & & & $\equiv 0.0$ \\
\hline $\mathrm{CaO}$ & 29.1 & 0.5 & 1.3 & 29.2 & 0.1 & 1.1 & -0.4 & 19.6 & 0.7 & 1.4 & 17.9 & 0.6 & 8.9 & +7.8 \\
\hline $\mathrm{TiO}_{2}$ & 2.17 & 3.0 & 1.3 & 2.38 & 1.1 & 1.0 & -8.7 & 0.063 & 30.3 & 1.0 & 0.070 & 15.3 & 2.5 & -9.7 \\
\hline $\mathrm{SrO}$ & 0.683 & 1.3 & 1.6 & 0.668 & 0.8 & 3.2 & +2.1 & 0.826 & 3.7 & 4.9 & 0.739 & 5.1 & 21.8 & +11.8 \\
\hline $\mathrm{Y}_{2} \mathrm{O}_{3}$ & 0.463 & 2.4 & 1.7 & 0.510 & 1.5 & 5.4 & -9.4 & & & & 0.0018 & 30.8 & 6.4 & \\
\hline $\mathrm{ZrO}_{2}$ & 1.67 & 2.0 & 3.3 & 1.50 & 3.2 & 12.0 & +11.3 & & & & 0.00088 & 29.1 & 2.6 & \\
\hline $\mathrm{Ia}_{2} \mathrm{O}_{3}$ & 1.29 & 1.1 & 1.3 & 1.37 & 1.5 & 7.2 & -6.2 & 0.038 & 16.3 & 1.1 & 0.038 & 31.8 & 24.4 & 0.9 \\
\hline $\mathrm{Sm}_{2} \mathrm{O}_{3}$ & 1.29 & 0.8 & 1.8 & 1.26 & 0.8 & 3.8 & +2.5 & & & & 0.011 & 31.9 & 14.6 & \\
\hline $\mathrm{Yb}_{2} \mathrm{O}_{3}$ & 1.22 & 0.7 & 2.4 & 1.21 & 0.9 & 3.8 & +1.0 & & & & 0.0021 & 33.0 & 5.7 & \\
\hline Sum & 99.3 & 0.7 & & 99.2 & & & & 100.8 & 0.4 & & 99.7 & & & \\
\hline
\end{tabular}

${ }^{*} \sigma_{\mathfrak{o}}=$ observed relative standard deviation of 10 analyses; $\sigma_{\mathfrak{c}}=$ counting statistics relative standard deviation; values of $\sigma_{d} / \sigma_{c}$ less than 2 indicate that starting materials are acceptably homogeneous. The IP sums are less than $100 \%$ hecause additional elements ( $\mathrm{Na}{ }_{2} \mathrm{O}$, $\mathrm{P}_{2} \mathrm{O}_{5}, \mathrm{~K}_{2} \mathrm{O}$ and $\left.\mathrm{FeO}\right)$ were measured, but not reported. $\ddagger \Delta=(\mathrm{EP} / \mathrm{IP}-1) \times 100$; i.e., percent difference between averages of $14 \mathrm{EP}$ and 5 IP analyses of glass and 9 EP and 5 IP analyses of anorthite. 


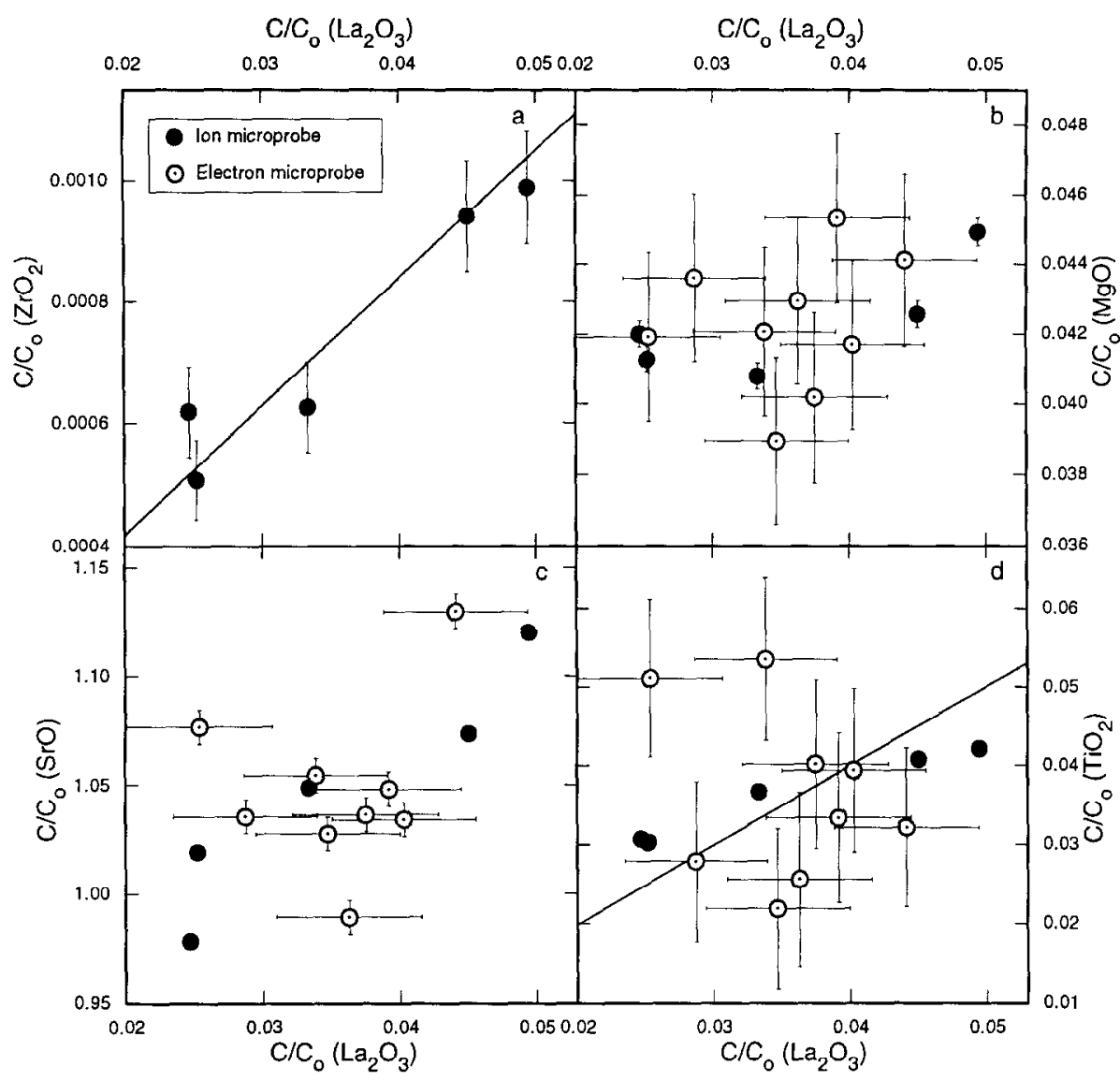

FIG. I. Interelement correlation plots vs. $\mathrm{La}_{2} \mathrm{O}_{3}$ for anorthite from sample 224-8. Average of electron probe data corrected to average of ion probe data via $\Delta$ values from Table 3 . Concentrations given relative to initial liquid concentration, $C_{\mathrm{o}}$. Error bars are one standard deviation; for the ion probe analyses of $\mathrm{La}, \mathrm{Sr}$, and $\mathrm{Ti}$ these are smaller than the plotted points. (a) The line in the $\mathrm{Zr}$-La plot corresponds to a constant partition coefficient ratio, and similar relations hold for $\mathrm{Sm}, \mathrm{Y}$, and $\mathrm{Yb}$ relative to $\mathrm{La}$ (see text). (b) $\mathrm{MgO}$ variations are much smaller than those for $\mathrm{La}$. There is some small scatter about the overall correlation in the ion probe data. (c) Sr variations are much smaller than those for $\mathrm{La}$. The positive correlation is somewhat surprising given that $\mathrm{Sr}$ is a compatible element. (d) Although well correlated, the percentage variation in $\mathrm{\Gamma i}$ is only about one-half that for $\mathrm{La}$, as illustrated by the reference line, whose slope is 1 .

$\pm 0.012, D(\mathrm{Yb}) / D(\mathrm{La})=0.062 \pm 0.004, D(\mathrm{Y}) / D(\mathrm{La})$ $=0.125 \pm 0.004$, and $D(\mathrm{Zr}) / D(\mathrm{La})=0.021 \pm 0.002$, where the error represents the sample standard deviation. Fig. 1c cannot be interpreted in this way because $\mathrm{Sr}$ is a compatible element in anorthite, and the $\mathrm{La}-\mathrm{Sr}$ correlation is unexpected.

\section{Calculation of Anorthite Partition Coefficients}

Ion probe analyses were made in interior regions of two crystals ( $A$ and $B$ ), at locations intermediate between core and rim. Two ion probe analyses for crystal B are systematically lower for all minor and trace elements than three analyses of crystal A. (This systematic intercrystal difference is not observed in the electron probe data.) Disequilibrium effects will tend to give high $D$ values for incompatible elements (here, all except $\mathrm{Sr}$ ), and from this point of view the lowest measured concentration should give the best estimates. $D$ values from ion probe data are thus based on the crystal $B$ analyses.

Both the electron and ion probe data refer to relatively small volumcs from individual crystals. In order to calculate a $D$ using a single point analysis, the amount of crystallization, $F_{i}$, for point $i$ must be known. We are not able to calculate $F_{i}$ exactly but, for samples such as 224-8 with relatively small degrees of crystallization, this is not a major source of error. We estimated $F_{i}$ from the location of the point in the crystal using a central section model which assumes: (1) the center of the crystal in the section corresponds to the point of nucleation, (2) the crystal nucleated on the liquidus, and (3) crystal growth is uniform, with the same crystal shape at all stages of growth. With these assumptions, $F_{i}=\left(r_{i} / R\right)^{3} F_{\max }$, where $R$ is the center-rim distance passing through analysis point $i, r_{i}$ is the distance from the center to the analysis point, and $F_{\max }$ is the total amount of crystallization ( 0.206 for $224-$ 8 ). Using the locations of the analysis points to obtain $r_{i}$ and $R$, values of $F_{i}$ were calculated for each. Combining these $F_{i}$ values with measured crystal $\left(C_{i}\right)$ and initial liquid $\left(C_{\mathrm{o}}\right)$ concentrations, $D$ values can be calculated for each point: $C_{i} / C_{\mathrm{o}}=D\left(1-F_{i}\right)^{(D-1)}$. The assumptions in the central section model will not be valid in general, but the errors introduced are not important. Average $D$ values calculated from crystal B ion probe data are given in Table 4. 
Table 4. Anorthite/liquid partition coefficients for a CAI liquid, from experiment 224-8.

\begin{tabular}{lc}
\hline & $\mathrm{D}^{*}$ \\
\hline $\mathrm{D}_{\mathrm{Mg}}$ & $0.0394 \pm 0.0000$ \\
$\mathrm{D}_{\mathrm{Ti}}$ & $0.0289 \pm 0.0001$ \\
$\mathrm{D}_{\mathrm{Sr}}$ & $1.00 \pm 0.03$ \\
$\mathrm{D}_{\mathrm{Y}}$ & $0.00299 \pm 0.00008$ \\
$\mathrm{D}_{\mathrm{ir}}$ & $0.00053 \pm 0.00007$ \\
$\mathrm{D}_{\mathrm{La}}$ & $0.0236 \pm 0.0007$ \\
$\mathrm{D}_{\mathrm{Sm}}$ & $0.00737 \pm 0.00001$ \\
$\mathrm{D}_{\mathrm{Yb}}$ & $0.00150 \pm 0.00008$ \\
$\mathrm{D}_{\mathrm{Y}} / \mathrm{D}_{\mathrm{La}}$ & $0.127 \pm 0.007$ \\
$\mathrm{D}_{\mathrm{Zr}} / \mathrm{D}_{\mathrm{La}}$ & $0.023 \pm 0.003$ \\
$\mathrm{D}_{\mathrm{Sm}} / \mathrm{D}_{\mathrm{La}}$ & $0.312 \pm 0.008$ \\
$\mathrm{D}_{\mathrm{Yb}} / \mathrm{D}_{\mathrm{La}}$ & $0.064 \pm 0.002$ \\
\hline
\end{tabular}

*Uncertaintics are the standard deviation of the two ion microprobe analyses of crystal B. From known sources of error, accuracy is better than $\pm 10 \%(1 \sigma)$, but systematic effects of disequilibrium partitioning cannot be assessed.

\section{Overview of the Perovskite Samples}

Although the runs have the same cooling histories (Table 2), perovskite in QPX-8 occurs as tabular, idiomorphic crystals up to $120 \mu \mathrm{m}$ across, whereas that in QPX-9 has an unusual, cross-shaped morphology. The latter grains are up to $100 \mu \mathrm{m}$ across and have rounded edges, unlike those in QPX-8, which are straight and angular. The QPX-9 sample contains small $(1-10 \mu \mathrm{m})$ crystals which, on the basis of texture, could be quench crystals. Electron probe analysis indicates that these are probably $\mathrm{Ti}^{+3}$-bearing pyroxenes. The uncertainties in the effects of the pyroxene crystallization on the measured glass composition lead to uncertainties in estimates of the amount of crystallization; our best estimate (from $\mathrm{Sm}$ and $\mathrm{Ca}$ in glass relative to the starting material) is around $17 \%$ pyroxene with about $3 \%$ perovskite. If pyroxene and perovskite crystallized more or less simultaneously with a total amount of crystallization equal to $17+3=20 \%$, perovskite should have been zoned in the highly compatible elements ( $\mathrm{L}$ a and $\mathrm{Sm}$ ), hut this is not observed. Thus, the homogeneity of the QPX-9 perovskite suggests that the bulk of the pyroxene crystallization occurred after perovskite. The amount of perovskite crystallization in the QPX-8 sample is also low $(1-4 \%)$ and difficult to measure; we adopt $2 \%$. Fortunately, only minor errors in $D$ values are introduced by the uncertainties in the amounts of crystallization.

\section{Perovskite Partitioning}

Although there are variations significantly greater than counting statistics, these are not important because counting statistics errors are small (Table 5). Thus, calculation of average compositions for the QPX-8 and QPX-9 samples is justified (Table 5). For QPX-8 glass, the analyses show small (maximum 6\% for $\mathrm{Sm}$ ) but systematic composition differences: points near crystals are lower in elements compatible in perovskite. The glass composition away from the crystals is tabulated in Table 5 .

The $\mathrm{CaO}$ contents of the synthetic perovskite are well below that of pure $\mathrm{CaTiO}_{3}(41 \mathrm{wt} \%$ ), indicating that REE + Y $\left(R^{+3}\right)$ enter the Ca site. The REEs and $Y$ enter via coupled substitutions in the Ti site to maintain the charge balance. In QPX-8 (high $f_{\mathrm{O}_{2}}$ ) possible coupled substitutions are $2 \mathrm{R}^{+3}$ $+\mathrm{Mg}^{+2} \leftrightarrows 2 \mathrm{Ca}^{+2}+\mathrm{Ti}^{+4}$ and $\mathrm{R}^{+3}+\mathrm{Al}^{+3} \leftrightarrows \mathrm{Ca}^{+2}+\mathrm{Ti}^{+4}$ where $\mathrm{R}^{+3}$ represents REEs and $\mathrm{Y}$. Allowing for possible $\mathrm{Al}$ and $\mathrm{Mg}$ substitutions which do not involve $\mathrm{R}^{+3}$, the number of REE + Y cations per 3 oxygen ions should be less than the number of $\mathrm{Al}$ cations plus twice the $\mathrm{Mg}$ cations. Table 5 shows that in QPX-8, however, $\mathrm{R}^{+3}=0.0929$ and $2 \mathrm{Mg}$ $+\mathrm{Al}=0.0688$. Magnesium and $\mathrm{Al}$ do not completely account for the observed REE + Y abundances in QPX-8 perovskite,

Table 5. Electron microprobe analyses of samples QPX-8 and QPX-9.

\begin{tabular}{|c|c|c|c|c|c|c|c|c|c|c|c|c|}
\hline & \multicolumn{7}{|c|}{$-\mathrm{QPX}-8$ (air)- } & \multicolumn{5}{|c|}{$\longrightarrow$ QPX-9 (low $\left.\mathrm{fO}_{2}\right)$} \\
\hline & \multirow{2}{*}{$\begin{array}{l}\text { Wi\% } \\
\text { oxide }\end{array}$} & \multicolumn{2}{|c|}{ Glass } & \multicolumn{4}{|c|}{-Perovskite_- } & \multicolumn{2}{|c|}{ _Class__ } & \multicolumn{3}{|c|}{ - Perovskite } \\
\hline & & $\begin{array}{l}\sigma_{\mathrm{o}}{ }^{*} \\
(\%)\end{array}$ & $\sigma_{\mathrm{o}} / \sigma_{\mathrm{c}}^{*}$ & $\begin{array}{l}\text { Wt\% } \\
\text { oxide }\end{array}$ & $\begin{array}{l}\sigma_{0}{ }^{*} \\
(\%)\end{array}$ & $\sigma_{\mathrm{o}} / \sigma_{\mathrm{c}}^{*}$ & $\begin{array}{l}\text { Cations } \\
\text { per } 30\end{array}$ & $\begin{array}{l}\text { Wt\% } \\
\text { oxide }\end{array}$ & $\begin{array}{l}\sigma_{0}{ }^{*} \\
(\%)\end{array}$ & $\begin{array}{l}\text { Wt\% } \\
\text { oxide }\end{array}$ & $\begin{array}{l}\sigma_{0}{ }^{*} \\
(\%)\end{array}$ & $\begin{array}{l}\text { Cations } \\
\text { per } 30\end{array}$ \\
\hline $\mathrm{MgO}$ & 8.12 & 2.3 & 5.5 & 0.208 & 7.3 & 1.6 & 0.0075 & 7.56 & 1.7 & 0.079 & 9.8 & 0.0029 \\
\hline $\mathrm{Al}_{2} \mathrm{O}_{3}$ & 17.1 & 1.6 & 5.0 & 1.88 & 2.1 & 1.9 & 0.0538 & 18.1 & 1.3 & 1.11 & 2.0 & 0.0323 \\
\hline $\mathrm{SiO}_{2}$ & 30.0 & 1.6 & 6.1 & $\leq 0.04$ & & & & 30.6 & 1.4 & $\leq 0.04$ & & \\
\hline $\mathrm{CaO}$ & 24.0 & 0.6 & 1.4 & 34.5 & 0.6 & 1.7 & 0.8974 & 24.6 & 0.7 & 31.1 & 0.6 & 0.8230 \\
\hline $\mathrm{TiO}_{2}$ & 13.3 & 1.1 & 0.7 & 51.0 & 0.6 & 0.8 & 0.9313 & 13.1 & 3.6 & 50.8 & 0.6 & 0.9441 \\
\hline SrO & 713 & 3.4 & 3.1 & 0.523 & 2.1 & 1.5 & 0.0074 & 0.775 & 1.8 & 0.568 & 2.1 & 0.0081 \\
\hline $\mathrm{Y}_{2} \mathrm{O}_{3}$ & 0.381 & 5.0 & 2.4 & 0.430 & 4.6 & 2.6 & 0.0056 & 0.386 & 4.1 & 0.720 & 2.1 & 0.0095 \\
\hline $\mathrm{ZrO}_{2}$ & 1.30 & 3.1 & 3.5 & 0.208 & 5.2 & 1.5 & 0.0025 & 1.45 & 2.5 & 0.278 & 5.0 & 0.0034 \\
\hline $\mathrm{La}_{2} \mathrm{O}_{3}$ & 0.990 & 0.9 & 0.7 & 4.66 & 1.3 & 2.6 & 0.0417 & 0.891 & 6.8 & 7.50 & 0.8 & 0.0684 \\
\hline $\mathrm{Sm}_{2} \mathrm{O}_{3}$ & 0.962 & 1.7 & 1.7 & 5.00 & 1.1 & 3.0 & 0.0419 & 0.864 & 7.9 & 7.35 & 1.3 & 0.0627 \\
\hline $\mathrm{Yb}_{2} \mathrm{O}_{3}$ & 0.986 & 0.9 & 1.1 & 0.505 & 5.4 & 4.5 & 0.0037 & 1.02 & 1.0 & 1.04 & 1.3 & 0.0078 \\
\hline Total & 97.9 & & & 98.9 & & & 1.9928 & 99.3 & & 100.5 & & 1.9622 \\
\hline$N^{i}$ & 8 & & & 22 & & & & 13 & & 11 & & \\
\hline
\end{tabular}

${ }^{*} \sigma_{\mathrm{o}}=$ observed relative standard deviation of 10 analyses; $\sigma_{\mathrm{c}}=$ counting statistics relative standard deviation; values of $\sigma_{\mathrm{o}} / \sigma_{\mathrm{c}}$ less than 2 indicate that starting materials are acceptably homogeneous. †Number of analyses. 
indicating the effect of a third substitution: $2 R^{+3}+\square \leftarrow$ $3 \mathrm{Ca}^{+2}$, where $\square$ represents a Ca-site vacancy. Roughly $1 \%$ vacancies in the $\mathrm{Ca}$ site are required to balance the observed $\mathrm{R}^{+3}$ abundances. Cation vacancies in materials with the perovskite structure have been described by SMYTH (1989).

The low- $f_{\mathrm{O}_{2}}$ perovskite, QPX-9, has higher $\mathbf{R}^{+3}$ contents than QPX-8 perovskite despite lower $\mathrm{Al}$ and $\mathrm{Mg}$ contents (last column, Table 5). This suggests that the coupled substitution $\mathrm{R}^{+3}+\mathrm{Ti}^{+3} \leftrightarrows \mathrm{Ca}^{+2}+\mathrm{Ti}^{+4}$ is possible at low $f_{\mathrm{O}_{2}}$. This would explain the low cation total obtained for QPX-9 perovskite when $\mathrm{Ti}$ is calculated as $\mathrm{Ti}^{+4}$, as well as the large difference between $\mathrm{R}^{+3}(0.148)$ and $2 \mathrm{Mg}+\mathrm{Al}(0.038)$. In QPX-9, the amount of trivalent $\mathrm{Ti}$ in addition to $\mathrm{Al}$ and $\mathrm{Mg}$ required to balance the observed $\mathrm{R}^{+3}$ content is about $11 \%$ of the total Ti. The SrO content of QPX-9 is the same as that of the QPX-8 perovskite ( Table 5) because Sr substitution is not dependent upon coupled substitutions.

To calculate perovskite $D$ values we treat the measured crystal concentrations as core values and divide by the initial liquid concentration ( $D_{\mathrm{c}}$, Table 6 ). For compatible elements $D_{c}$ will if anything, tend to be slightly low. The true $D$ values will be bracketed between the core values and a measured, apparent $D_{\mathrm{m}}$, obtained by dividing the crystal concentration by the measured concentration in the co-existing glass. For compatible elements these are upper limits to the true $D$ s, assuming fractional crystallization. Table 6 shows that the differences between $D_{\mathrm{c}}$ and $D_{\mathrm{m}}$ are small.

\section{DISCUSSION}

\section{Anorthite Partitioning}

\section{Comparison with previous studies}

Figure 2 compares our anorthite REE $D$ pattern with literature data for calcic plagioclases. Our REE $D$ patterns, along with those of PHINNEY and MORRISON (1990) for An84 (phenocryst-matrix) or An95 (experimental), define steeper slopes than any of the previous literature patterns. As shown by the shaded region on Fig. 2, basalt phenocryst-matrix $D$ values for $\mathrm{Yb}$ from the literature are up to a factor of 25 higher than ours, most likely because of severe problems in obtaining ultraclean plagioclase separates, as also concluded by PHINNEY and MORRISON (1990). In general, it is likely

Table 6. Perovskite partition coefficients for experiments QPX-8 and QPX-9, determined by electron microprobe.

\begin{tabular}{lcccc}
\hline & \multicolumn{3}{c}{ QPX-8 } & \multicolumn{2}{c}{$\begin{array}{c}\text { QPX-9 } \\
\text { air }\end{array}$} & \multicolumn{2}{c}{$f_{\mathrm{O}_{2}}=10^{-16} \mathrm{~atm}$} \\
& $\mathrm{D}_{\mathrm{m}}$ & $\mathrm{D}_{\mathrm{c}}$ & $\mathrm{D}_{\mathrm{m}}$ & $\mathrm{D}_{\mathrm{c}}$ \\
\hline $\mathrm{D}_{\mathrm{Mg}}$ & 0.026 & 0.025 & 0.0104 & 0.0096 \\
$\mathrm{D}_{\mathrm{Al}}$ & 0.11 & 0.11 & 0.061 & 0.064 \\
$\mathrm{D}_{\mathrm{Si}}$ & $\leq 0.001$ & $\leq 0.001$ & $\leq 0.001$ & $\leq 0.001$ \\
$\mathrm{D}_{\mathrm{Sr}}$ & 0.73 & 0.70 & 0.73 & 0.77 \\
$\mathrm{D}_{\mathrm{Y}}$ & 1.13 & 1.11 & 1.87 & 1.86 \\
$\mathrm{D}_{\mathrm{Zr}}$ & 0.16 & 0.16 & 0.19 & 0.21 \\
$\mathrm{D}_{\mathrm{La}}$ & 4.7 & 4.4 & 8.4 & 7.1 \\
$\mathrm{D}_{\mathrm{SIn}}$ & 5.2 & 4.8 & 8.5 & 7.1 \\
$\mathrm{D}_{\mathrm{Yb}}$ & 0.51 & 0.52 & 1.02 & 1.06 \\
\hline
\end{tabular}

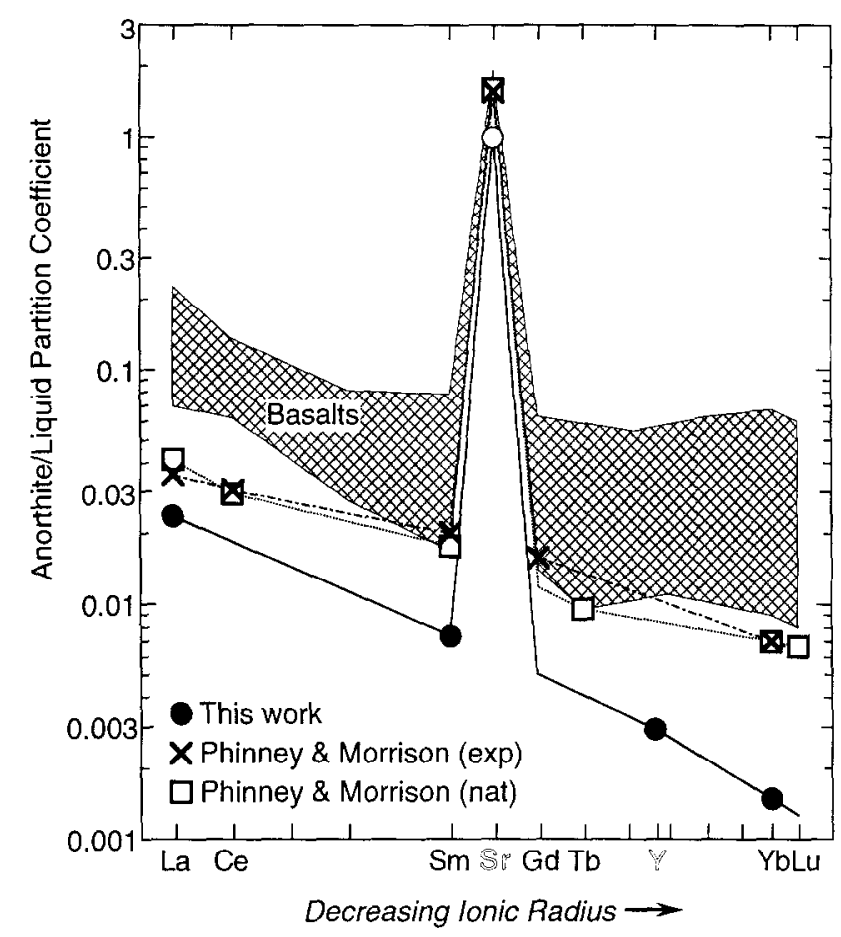

FIG. 2. REE partition coefficient pattern for anorthite. Strontium is plotted at the position of divalent Eu. Yttrium is plotted at the position corresponding to its ionic radius. Our data, and the partition coefficients of PHINNEY and MORRISON (1990), both experimental (exp) and phenocryst-matrix (nat), show steeply dipping REE patterns compared to older literature values, as illustrated by the shaded band showing basalt phenocryst-matrix data compiled by PHINNEY and Morrison (1990). PHINNEY and MORRISON (1990) did not measure $D$ for Sr, so we plotted the $D$ for Sr measured by WEILL and MCKAY (1975). For at least the heavy REE the older basalt data should be regarded as upper limits.

that plagioclase $D$ values from the older literature, for at least the HREEs, should be regarded as upper limits. The steeply decreasing plagioclase REE $D$ pattern for Archean basaltic dikes from PHINNEY and MORRISON (1990) is qualitatively similar to ours and to their experimental pattern for a lunar basaltic composition. Thus, there are no inherent large systematic differences between experimental and phenocrystmatrix $D$ patterns.

Summary. Taking the literature at face value leads to a range of REE $D$ values in plagioclase which is much too large.

However, $D$ values do vary with temperature, crystal composition, and liquid composition. Relative to the total range indicated by Fig. 2, our La $D$ is close to those of PHINNEY and MORRISON (1990) (0.024 vs. 0.036-0.042); however, our $\mathrm{Yb} D$ is the lowest yet reported, a factor of about 5 lower than either the phenocryst-matrix or the experimental values of PHINNEY and MORRISON (1990). These differences are apparently real. For example, PHINNEY and MORRISON (1990) predict melt REE patterns for the Bad Vermillion Lake anorthosite, using their $D$ values, which correspond to the range of patterns for basalts contemporaneous with the anorthosites (their Fig. 14), but if our $Y \mathrm{~b} D$ had been used, patterns with a strong HREE excess would have been predicted, outside the measured basalt range. Thus, our HREE 
$D$ values, determined for a CAI composition, appear to be lower than those applicable to terrestrial basalts. This difference cannot be due to crystal chemistry, but the relative importance of bulk composition and temperature in determining the differences in $\mathrm{Yb} D$ cannot be separated.

Even if all $D$ values for $\mathrm{Yb}$ in the older literature are ascribed to impurities, it is difficult to draw the same conclusion for La. Some La $D$ values of the order of 0.1 are indicated unless all mineral separate impurities have REE $D$ patterns that are highly enriched in LREEs. It is more reasonable to assume that the most likely impurities have REE $D$ patterns that are relatively flat (e.g., apatite or liquid inclusions) or HREE-enriched (e.g., zircon). A range of La $D$ values of at least a factor of 5 is indicated.

Our $D$ values apply to slightly higher temperatures than the $1200^{\circ} \mathrm{C}$ of PHINNEY and MORRISON (1990). The compositions of plagioclases studied by PHINNEY and MORRISON (1990) (phenocryst, An84; experimental, An95) are similar to ours; however, our bulk composition is different. Thus, the similar La $D$ values (Fig. 2) suggest that differences in our CAI liquid composition from those of PHINNEY and MORRISON (1990) are not of major importance in LREE partitioning for anorthitic plagioclase or that temperature and liquid composition effects are compensating. At $1200^{\circ} \mathrm{C}$ the La $D$ values from the experiments of DRAKE and WEILL (1975) for more sodic plagioclases are much higher, around 0.20 , suggesting a significant plagioclasc composition effect, possibly controlled by crystal chemistry or by some aspect of liquid composition (e.g., $\mathrm{Na} / \mathrm{Al}$ ) not present in our composition or those of PHINNEY and MORRISON (1990; lunar basalt, terrestrial anorthosite).

As appropriate for CAI redox conditions, $\mathrm{Sr}$ is plotted at the position of divalent Eu on Fig. 2, although there is some evidence for $\mathrm{Sr}$ and Eu fractionation in CAIs (DAvIS et al., 1992). Our $\mathrm{Sr} D$ is the lowest value reported for plagioclase, but this is consistent with a factor of 8 decrease in $\operatorname{Sr} D$ from Ab to An (Smith and Brown, 1988; Fig. 14-24).

The inverse correlation of $\mathrm{Sr} D$ with plagioclase anorthite content has been emphasized by BLUNDY and WOOD (1991) who argue that $\mathrm{Sr}$ (and $\mathrm{Ba}$ ) partitioning in plagioclase is primarily controlled by crystal chemistry. This view has been challenged by MORSE (1992) who maintains that liquid composition is the dominant control, specifically that $1 /$ $D(\mathrm{Sr})$ is proportional to normative feldspar content of the liquid. Our data, on a very different composition than those considered by the above authors, offer an interesting test of the alternative proposed systematics. The empirical equation for the Sr weight $D$ vs. An content from Bu UNDY and WooD (1991) predicts $D(\mathrm{Sr})=1.07$, close to our measured value of 1.00 . However, for the various liquid activity-composition models discussed by BLUNDY and WOOD (1991) molar $D$ values (presumably more fundamental) calculated from our data do not agree well with the systcmatics displayed on Figs. 4, 5 of BLUNDY and WOOD (1991). Even considering alternatives to a classical CIPW norm which involve melilite liquid components, normative feldspar concentrations for our liquids are in the range of $25-40 \%$ molar, thus much higher $\mathrm{Sr}$ $D$ values than we observe would have been expected from Fig. 1 of MORSE (1992). It is possible that both the BLUNDY and WOOD (1991) and MORSE (1992) interpretations are inadequate for a quantitative understanding of Sr partitioning in plagioclase over a wide range in bulk compositions.

The Sr $D$ of WEILL and MCKAY (1975) for anorthite from a Na-free lunar basalt bulk composition is only $36 \%$ higher than for our CAI composition. It is possible that variations due to temperature are canceling those due to bulk composition in this comparison but, taking the $36 \%$ difference at face value and comparing it to the overall factor of 8 range, crystal chemistry does appear to be a significant factor in $\mathrm{Sr}$ partitioning in plagioclase.

PHINNEY and MORRISON (1990) report an experimental $\mathrm{Mg} D$ of 0.043 for the lunar basalt bulk composition of MCKAY (1982). LONGHI et al. (1976) found 0.041 for a variety of alkali-free basaltic compositions. These $D$ values are only slightly higher than ours $(0.039$; Table 4$)$. Two phenocryst-matrix measurements (PHINNEY and MORRISON, 1990 ) gave lower values, 0.023 and 0.020 , but these may reflect subsolidus re-equilibration (PHINNEY, 1991). For Ti, PHINNEY and MORRISON (1990) report an experimental $D$ of 0.034 , close to our 0.029 ; however, as with $\mathrm{Mg}$, the phenocryst-matrix $D$ for Ti are lower (two measurements: 0.021 and 0.011 ). There is no evidence for strong bulk composition effects in $\mathrm{Mg}$ or Ti partitioning in plagioclase.

Crystal chemistry could be the dominant factor in determining $\mathrm{Sr}$ and LREE partitioning into plagioclase, although we cannot rule out possible canceling effects of temperature and liquid composition. For the HREE, liquid composition or temperature effects must be invoked to explain differences in $\mathrm{Yb} D$ values for highly anorthitic plagioclases.

\section{Comparison with CAI anorthite data}

Magnesium and titanium concentrations. Because anorthite is a late phase in CAIs, some understanding of the complete crystallization history is required in order to predict $\mathrm{Mg}$ and Ti concentrations in anorthite; however, the task is not as formidable as it might appear at first glance. In fact, these quantitative comparisons are more of an internal consistency check of our understanding of CAI liquid crystallization than a modeling exercise.

Type B CAIs have cooled at sufficiently high rates to suppress anorthite nucleation relative to pyroxene (MACPHERSON et al., 1984; STOLPER and PAQUe, 1986). Thus, it is necessary to consider disequilibrium crystallization models, but the required data for such models are available. We focus on the well-studied Allende Type B 1 inclusions TS23, IS34, and TS33. Petrographically, these CAIs appear to have had a simple cooling history. Degrees of suppression of pyroxene and anorthite crystallization are parameters for this calculation and will differ among inclusions. Details of the calculations are given in Appendix A.

Figure 3 compares predictions of a standard model (Appendix A) with ion probe measurements of anorthite from inclusions TS23, TS34, and TS33 and with ion and electron probe measurements of Vigarano inclusion 1623-8 (MACPherson and Davis, 1993). The predicted Mg concentrations on Fig. 3 approach the observed range only for anorthite formed at total amounts of crystallization greater than $90 \%$. In contrast, for $F>90 \%$ the calculated anorthite Ti concentrations for the standard models are below the measurcd val- 


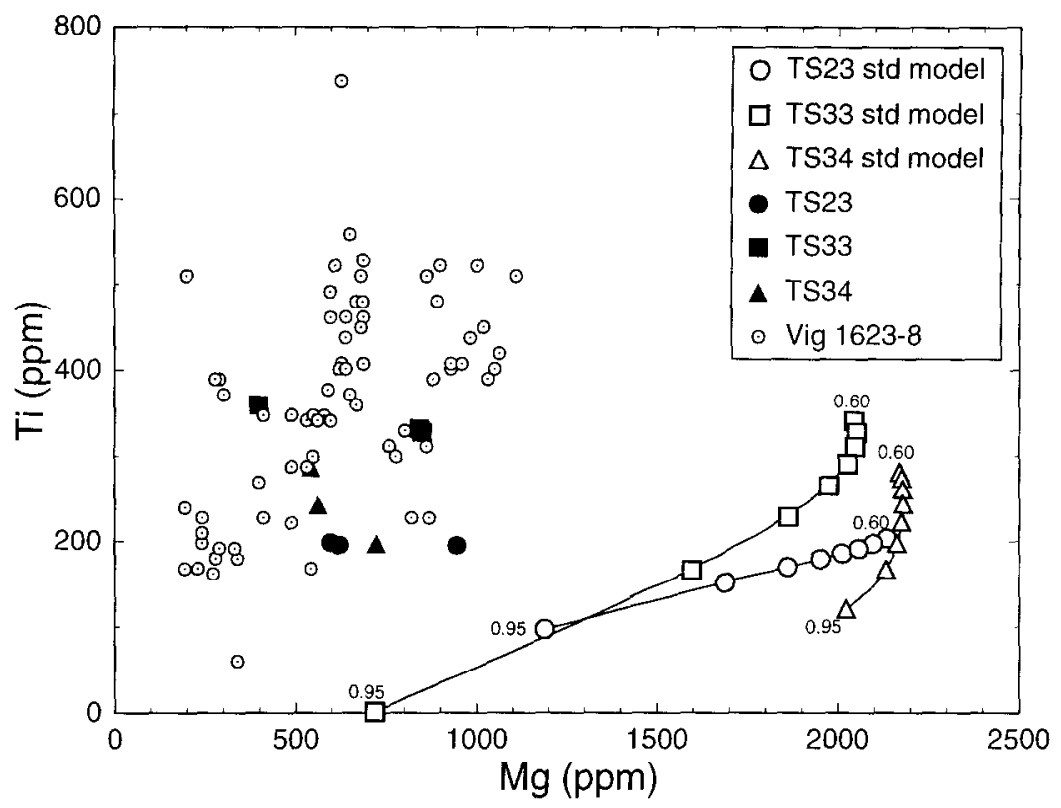

FIG. 3. Comparison of predicted trends for $\mathrm{Mg}$ and Ti concentrations in anorthite with observed concentrations in Type B CAIs. Numbers refer to fraction crystallized $(F)$. Points on model curves are separated by $5 \%$ intervals in $F$ beginning at onset of pyroxene crystallization $\left(F=F_{\mathrm{p}}=0.6\right)$ and ending at $F=0.95$. The curves for Allende inclusions TS23, TS33, and TS34 refer to a standard model in which anorthite does not nucleate and $D$ for $\mathrm{Ti}^{+3}\left(D_{3}\right)$ is assumed to be 0 . For TS23 and TS33 the calculated curves approach the observed $\mathrm{Mg}$ range as $F$ approaches $95 \%$, but the predicted Ti tends to be systematically low. At lower $F$, model Ti agrees with measured $\mathrm{Ti}$ but calculated $\mathrm{Mg}$ concentrations are high.

ues, whereas for TS33 and TS34 they are in the observed range for lower values of $F$. The calculations fail to describe $\mathrm{Mg}$ and Ti simultaneously.

The standard models assume that only pyroxene and melilite crystallize in stage 3 , so the calculated trends on Fig. 3 can be thought of as either representing the composition of trace amounts of anorthite or the composition of the first formed anorthite (core) at the value of $F$ corresponding to the position along the curve. Once anorthite nucleates, calculations (not shown) indicate that subsequent changes in the $\mathrm{MgO}$ and $\mathrm{TiO}_{2}$ contents in the liquid (and thus in anorthite) are relatively small, reflecting a delicate balance between the removal of $\mathrm{MgO}$ and $\mathrm{TiO}_{2}$ from the liquid by pyroxene and their increase by anorthite crystallization. In the standard models, at high $F(>90 \%)$ the uncrystallized anorthite effectively dilutes the liquid, lowering $\mathrm{Mg}$ concentrations in anorthite toward the range observed. For TS34, with only $0.7 \%$ anorthite, calculated $\mathrm{Mg}$ concentrations in anorthite are always well above observations. Thus, even for high $F$, there is agreement for $\mathrm{Mg}$ only when anorthite nucleation does not occur, i.e., $F_{\text {an }}>95 \%$ and then only for TS33. Anorthite from Vig 1623-8 has $\mathrm{Mg}$ and Ti contents in the same range as TS23, TS33, and TS34 (also Sr, Y, and REEs); however, this inclusion appears to have experienced remelting after alteration (MACPHERSON and DAVIS, 1993), and thus has had a more complex history than is inferred for the $\mathrm{Al}$ lende inclusions considered here.

Focusing on $\mathrm{Mg}$ alone, comparison of the standard models for the three inclusions (Fig. 3) shows that predictions are slightly sensitive to modes and to average $\mathrm{MgO}$ content in pyroxene (i.e., to bulk composition). Nevertheless, assuming that the modal and compositional variation of these three inclusions adequately defines the true observational range, it is unlikely that uncertainties in modes or bulk composition can account for the overall disagreement in $\mathrm{Mg}$ between calculations and observations. However, if the alteration products, abundant in Allende Type B CAIs and assigned to melilite in computing modes (BECKETT, 1986), were instead formed primarily from anorthite, this would substantially increase anorthite modes and lead to lower predicted anorthite $\mathrm{Mg}$ contents for $F$ close to $F_{\mathrm{p}}$. This explanation is admittedly speculative and has not been proposed from any petrographic study of CAIs, but it probably cannot be ruled out. RUZICKA and BOYNTON ( 1993) have proposed that anorthite in rims on Vigarano CAIs alters before melilite. Alternatively, it is conceivable that our measured $\mathrm{Mg} D$ values are systematically high because of disequilibrium effects, accounting for the $\mathrm{Mg}$ discrepancies on Fig. 3. In this case the calculated Ti should also be high, but this is not observed. We consider this alternative unlikely. Finally, differences in $\mathrm{Mg} D$ values due to small differences hetween our 224 composition and those of the actual CAIs cannot be ruled out; however, this would be surprising in view of the similarity of our $\mathrm{Mg} D$ values with those of LONGHI et al. (1976) or PHINNEY and MORRISON (1990) on basaltic compositions.

A separate conclusion, almost independent of assumptions, is that anorthite which formed at $F$ close to $F_{\mathrm{p}}$ would have $\mathrm{Mg}$ concentrations much higher than those observed. Thus, the $\mathrm{Mg}$ concentrations in type B CAI liquids appear to decrease in the interval between pyroxene and anorthite ap- 
pearance (stage 3; see Appendix A) even though the $\mathrm{Mg}$ concentration in pyroxene is increasing during stage 3 , as indicated by the pyroxene zoning patterns (SIMON et al., 1991).

A plausible explanation for the differences in $\mathrm{Mg}$ on Fig. 3 is subsolidus re-equilibration (most likely with pyroxene). Such re-equilibration for $\mathrm{Mg}$ (but not for $\mathrm{Ti}$ ) has been proposed for terrestrial and lunar anorthosites (PHINNEY, 1991) and for eucrites (PHINNEY et al., 1993). For the anorthosites, equilibration timescales of $10^{8} \mathrm{y}$ are proposed. If such time scales are necessary, it is unlikely that subsolidus re-equilibration is important for anorthite in CAIs. If CAI anorthites have re-equilibrated, the inferred anorthosite timescales would not be applicable.

Summary. Assuming that anorthite modes have not been seriously underestimated, that our measured $D$ values are relevant, and that the $\mathrm{Mg}$ contents in anorthite have not been affected by secondary processes, then very late crystallization of CAI anorthite $\left(F_{\text {an }}>90\right)$ is a possible interpretation of Fig. 3, implying that $F_{\text {an }} \gg F_{\mathrm{p}}$. At face value the TS34 data cannot be cxplaincd, but this may be a reflection of the anomalously low modal anorthite (Table A1). It is difficult to obtain an accurate mode for trace phases. Perhaps the section on which this mode was determined was statistically anomalous in this respect.

Considering only Ti concentrations, agreement is obtained for low values of $F_{\text {an }}$. There is thus no problem with the standard model for $\mathrm{Ti}$ alone. Because the $\mathrm{Mg}$ data suggest $F_{\text {an }}>90 \%$, however, the calculated $\mathrm{Ti}$ contents are too low (Fig. 3). There are, however, a number of possibilities for reconciling the Ti data with $F_{\text {an }}>90 \%$ :

1) Our assumption of zero $D$ for trivalent $\mathrm{Ti}\left(D_{3}\right)$ in the standard model (Appendix A) may be incorrect. Strictly speaking, the standard model calculates a lower limit to the Ti content of anorthite. Calculations assuming equal $D$ values for trivalent and tetravalent $\operatorname{Ti}\left(D_{3}=D_{4}\right)$ increase the predicted Ti concentrations by factors of 3-4 at all $F$ for all inclusions. For $F_{\text {an }}=90-95 \%$ calculated Ti contents are low by factors of $2-8$, so this is a possible alternative.

2) The observed Ti contents in anorthite may be high due to disequilibrium effects. Magnesium might be less affected due to more rapid diffusion in the liquid. Mclilite trace element contents in these same inclusions appear to be dominated by disequilibrium effects (DAVIS et al., 1992), but it cannot automatically be concluded that disequilibrium effects will dominate anorthite trace element partitioning as well.

3) Very late crystallization of anorthite might occur from liquids with higher Ti concentrations than those calculated with the standard model. For $F_{\text {an }}>95 \%$, Ti concentrations in anorthite might increase, although the cores of anorthite crystals should still have low Ti. In the last 5\% of crystallization the evolution of the liquid composition is very different from stage 3. For example, for TS23, 3/ 5 of the last $5 \%$ crystallized is anorthite, causing liquid composition trends for $\mathrm{Mg}$ and $\mathrm{Ti}$ to be dominated by anorthite. For TS33, 4/5 of the last $5 \%$ would be anorthite. Unless effective pyroxene $D$ values for Ti are high $(>2.5$ for TS23; $>5$ for TS33), both $\mathrm{Mg}$ and Ti concentrations in the liquid would increase. Thus, the last $5 \%$ crystalli- zation would be very different from stage 3 , where pyroxene crystallization depletes $\mathrm{Mg}$ and $\mathrm{Ti}$ in the liquid. If both $\mathrm{Mg}$ and $\mathrm{Ti}$ concentrations increase in the last 5\% of crystallization, then the trends shown on Fig. 3 for the standard model for $F<95 \%$ will reverse, and the curves will double back on themselves. Increasing $\mathrm{Mg}$ in the liquid during anorthite crystallization would also explain a kink in the observed MgO-Ti composition trends in pyroxene at high $F$ (SIMON et al., 1991; their Fig. 6). Negative Ti-REE correlations (discussed below) suggest that $\mathrm{Ti}$ in the liquid decreases during anorthite crystallization, in disagreement with alternative (3).

Alternative (3) is also supported by a good $\mathrm{Mg}-\mathrm{Na}$ correlation for type B CAI anorthite (Fig. 4). For a given inclusion the individual analyses presumably refer to different degrees of crystallization of a single liquid. Assuming that the $\mathrm{Na}$ is primary (of igneous origin) and that later-crystallizing anorthite has higher $\mathrm{Na}$, the correlation suggests that $\mathrm{Mg}$ was increasing in the liquid over the course of anorthite crystallization. (The Na contaminant in 224-8 defines an effective anorthite $D$ of 0.5 , and this supports the general expectation that anorthite with higher $\mathrm{Na}$ content crystallizes later.) Alternatively, if the $\mathrm{Na}$ variations in anorthite are interpreted as reflecting progressive $\mathrm{Na}$ loss by volatilization (MACPHERSON and DAvis, 1993), then anorthite with lower $\mathrm{Na}$ would have formed later, and $\mathrm{MgO}$ in the liquid would be inferred to decrease during anorthite crystallization, opposite to the first alternative. Cathodoluminescence patterns in anorthite from type B CAIs are partially correlated with $\mathrm{Na}$ and Mg distributions (HuTCHEON et al., 1978; MACPHERSON and DAvis, 1993). These patterns can be complex (e.g., Fig. 4

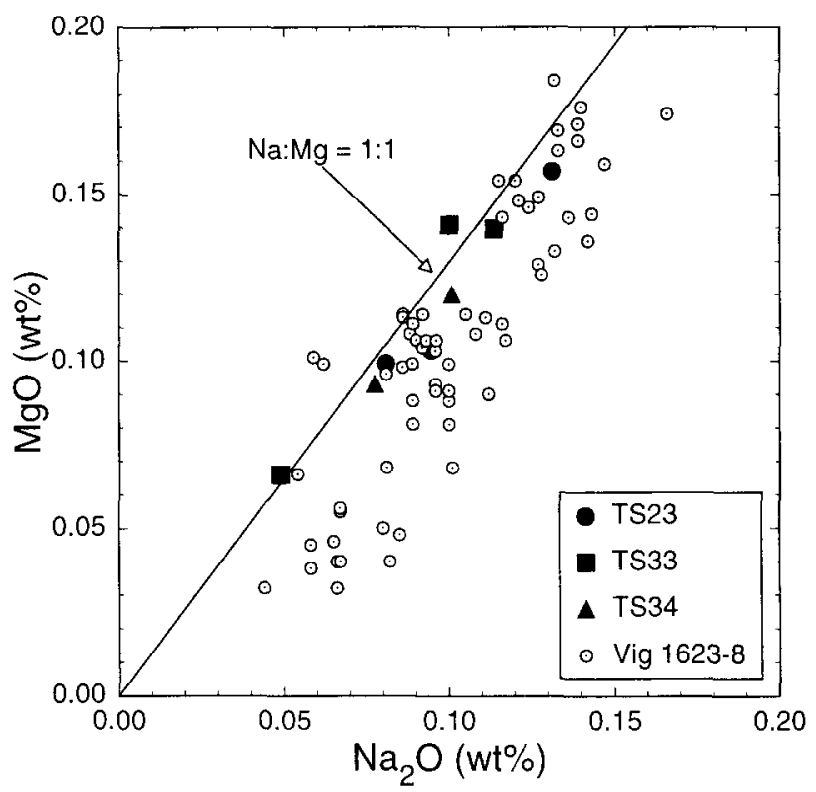

FiG. 4. $\mathrm{Na}_{2} \mathrm{O}$ and $\mathrm{MgO}$ are correlated in anorthite from four different type $\mathrm{B} \mathrm{CAI}$ inclusions. If the $\mathrm{Na}$ content of anorthite increases with increasing amount of crystallization, this indicates that $\mathrm{Mg}$ was increasing in the liquid during anorthite crystallization. If the $\mathrm{Na}_{2} \mathrm{O}$ variations represent progressive volatilization, the opposite conclusion about $\mathrm{MgO}$ is drawn. 
of HUTCHEON et al., 1978) and not easily explained by crystalliquid partitioning. But, allowing for impinging growth of separately-nucleated crystals, it cannot be safely concluded that the cathodoluminescence data rule out an igneous origin for the $\mathrm{Mg}$ distributions in anorthite.

Crystallization histories of CAIs are more complex than assumed in our calculations; however, in principle, the deviations of observations from predictions should constrain the processes involved. For example, it may be that our inability to account simultaneously for the $\mathrm{Mg}$ and $\mathrm{Ti}$ in anorthite by fractional crystallization modeling indicates that some of these concentrations do not reflect igneous processes but, instead, are set by subsolidus re-equilibration with pyroxene or by secondary alteration processes. An alternative possibility is that anorthite crystallization is very late, but this is subject to additional testing from REE, Y, and Sr data. At present it is imprudent to select a preferred alternative.

$R E E, Y$, and Sr Patterns. Here we focus on disequilibrium crystallization models as for $\mathrm{Mg}$ and $\mathrm{Ti}$; however, for general reference, we have also calculated what would be expected from the equilibrium crystallization experiments of STOLPER (1982). Details of the calculations are given in Appendix B. Calculated Cl-normalized anorthite REE patterns for anorthite are compared with ion probe data in Fig. 5.

On Fig. 5, Y is plotted at the position of its ionic radius, and $\mathrm{Sr}$ is assumed to be a proxy for divalent $\mathrm{Eu}$. In all cases the patterns are steeply dipping, showing the imprint of the $D$ pattern. The patterns for all models are similar. Figure 5 shows that, to a first approximation, absolute REE concentrations in anorthite depend only on the amount of crystallization $(F)$. The lowest curve on Fig. 5 corresponds to the cores of anorthite crystals formed by the STOLPER (1982) crystallization sequence, at $F=37 \%$. On Fig. 5 the highest concentrations are for $F=95 \%$. As the amount of liquid approaches zero ( $F$ approaches $100 \%$ ), extremely high REE concentrations in anorthite are produced, but these would be found in the outermost rims of grains, which are hard to analyze by any technique, so $F=95 \%$ is a reasonable upper bound for comparison with analyses in the interiors of grains. Three different models are shown for $F=95 \%$ with variations in the other parameters, but on the log scale of Fig. 5 the differences among these models appear small. The models shown are for inclusion TS34. Results for TS33 and TS23 are similar. The calculated patterns for $F=95 \%$ are close to the observed range, although the average observed REE pattern for four type B CAIs lies above the $F=95 \%$ models, suggesting very late crystallization of anorthite, in general agreement with petrographic observations (SIMON et al., 1991). Individual type B CAls show variations in the enrichment factors from the assumed $17 \times \mathrm{CI}$. If these inclusions are assumed to have an average enrichment factor of $25 \times \mathrm{CI}$, a good match to the average observed pattern is obtained for $F=90-95 \%$. Bulk chemical data are unavailable for the inclusions studied here. In any case, to the extent that the analyses correspond to cores (i.e., first-formed anorthite), anorthite nucleation appears to have been suppressed until $F$ $=90-95 \%$, agreeing with a possible interpretation (alternative 3) of the $\mathrm{Mg}$ data above. This issue is examined further below.

Although the light REE data can be described by models with $F_{\text {an }}>95 \%$, information is considerably subdued in con-

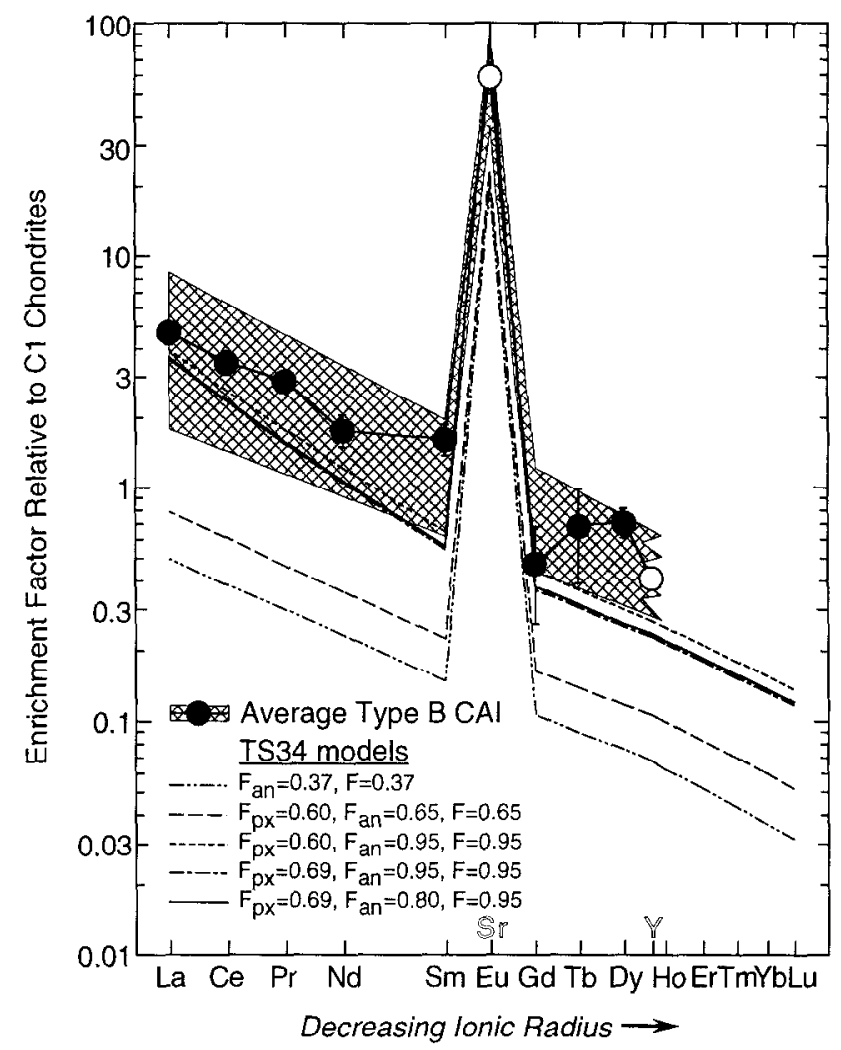

FIG. 5. Comparison of predicted REE abundances in anorthite with the range (shaded region) and average pattern based on seventeen analysis spots in the four type B CAIs from Fig. 3. To a first approximation REE concentrations depend only on the amount of crystallization $(F)$. Thus, the lowest REE concentrations are for the first anorthite formed at $F_{\text {an }}=F=37 \%$ for the STOLPER (1982) crystallization sequence, and all patterns for $F=95 \%$ are similar, independent of other model parameters. In general any REE patterns lying between that for $F=37 \%$ and those for $F=95 \%$ are possible. The observed anorthite range and average pattern is close to the $F=95 \%$ models, but distinctions are suppressed by the multi-decade log plot.

ventional multi-decade log scale REE pattern plots such as Fig. 5. Use of La-Sr-Y correlation plots (Figs. 6, 7) is better because these elements are readily fractionated; moreover, the most reliable data are used. On Fig. 6 the data points and model curves define similar concave-downward trends, reflecting the preferential removal of $Y$ relative to La by pyroxene. Lanthanum concentrations depend almost entirely on $F$, but $\mathrm{Y}$ concentrations are also sensitive to the amount of pyroxene crystallization. With $F<95 \%$, calculated $\mathrm{La}$ and $Y$ concentration trends (Fig. 6) seem low for TS23 and TS34. For $F=85-95 \%$, calculated La concentrations match those for TS33, but $\mathrm{Y}$ is low. Calculated concentrations rise rapidly for $F>95 \%$, so at $F=96-97 \%$, the calculated La and $\mathrm{Y}$ concentrations for TS34 and TS23 would match observations. The analyses of TS34 show some tendency to lie below the trend of the other data on Fig. 6.

Independent of models, the measured data define a reasonable trend on Fig. 7; however, the variations mainly represent systematic differences among inclusions rather than being defined by an individual inclusion. Only pyroxene has sufficiently high $D$ values to fractionate Y from La. Thus La/ 


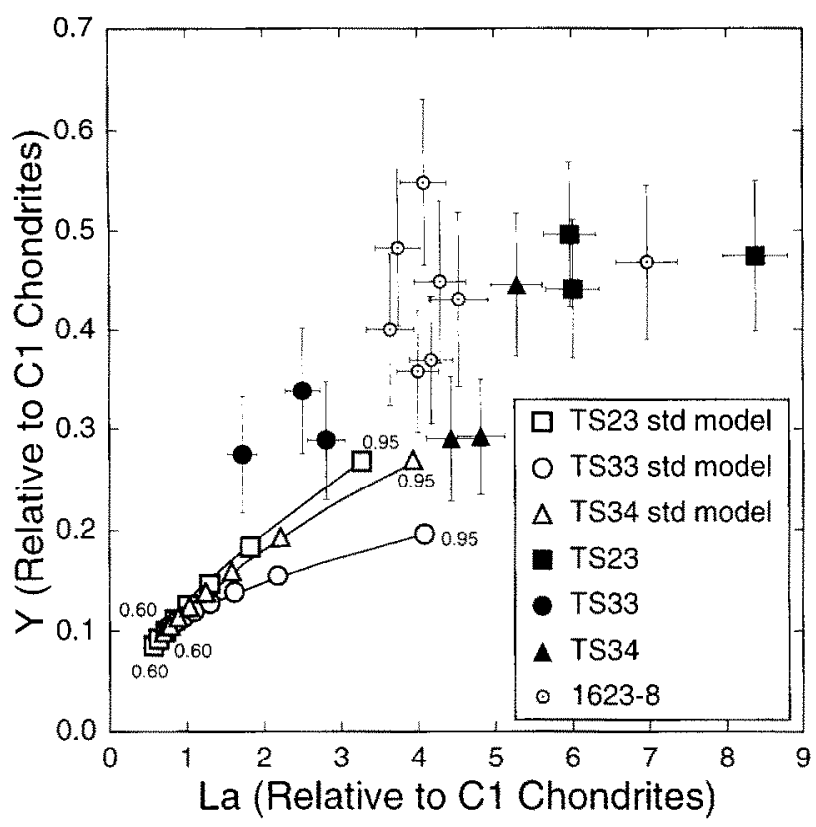

FIG. 6. Comparison of observed $\mathrm{Y}$-La interelement trends in anorthite with model predictions. Numbers on model curves refer to fraction crystallized $(F)$. Points along the model curves correspond to intervals of 0.05 in $F$, beginning with $F=F_{p}=0.6$, and ending at $F=0.95$. Lanthanum depends primarily on $F$, but pyroxene crystallization removes significant amounts of $Y$, producing curvature. TS33 has higher modal pyroxene and thus lower $\mathrm{Y}$ for a given $\mathrm{La}$ or for a given $F$. Varying $F_{\mathrm{p}}$ and $F_{\text {an }}$ produces minor changes in the predicted trends. Except for TS33, the observations can be described if measured grains correspond to $95 \%$ or greater crystallization.

$\mathrm{Y}$ is primarily a measure of the amount of pyroxene crystallization, and all models define similar trends on Fig. 7. The measured La/Y ratios for TS33 on Fig. 7 lie below the calculated trends, although data for the other inclusions are reasonably consistent with the models for high values of $F$. Considering only $\mathrm{Sr}$, models with $F>80 \%$ match the observed range for all inclusions. Disequilibrium incorporation of significant amounts of $\mathrm{Sr}$ in early melilite, as documented by DAvis ct al. (1992), should make the calculated Sr concentrations high, contrary to observation. Thus the agreement between calculations and observations for $\mathrm{Sr}$ on Fig. 7 could be fortuitous. One interpretation of Fig. 5 is that the bulk concentrations of refractory lithophile trace elements in these Allende inclusions are about $25 \times \mathrm{Cl}$, as opposed to the $17 \times \mathrm{CI}$ assumed in the modeling. Assuming $25 \times \mathrm{Cl}$ improves the agreement somewhat between models and all data on Fig. 6 and for TS33 on Fig. 7. The calculated trends for $25 \times \mathrm{CI}$ lie distinctly below the data for TS23 and TS34 on Fig. 7, but this could be explained by disequilibrium incorporation of $\mathrm{Sr}$ in melilite in these CAls. Thus, a consistent picture of REEs, $Y$, and $\mathrm{Sr}$ can be obtained with bulk abundances of around $25 \times \mathrm{CI}$.

Figure 8 compares predictions and observations for $\mathrm{Ti}$ and La. The observations define an apparent inverse trend which is suggestive of decreasing $\mathrm{Ti}$ concentrations in the liquid during anorthite crystallization. This would contradict an interpretation of the $\mathrm{Mg}$ - $\mathrm{Ti}$ data in which anorthite crystallization occurred at $F>95 \%$ and $\mathrm{Ti}$ concentrations in the liquid were increasing for $F>95 \%$. The model calculations show a decreasing trend for $F<95 \%$. The issue is what happens to Ti for $F>95 \%$. A well-defined negative correlation is also observed for Ti and Sr. However, the observed trends result from the juxtaposition of data from different inclusions. A firm conclusion that $\mathrm{Ti}$ concentrations in the liquid were decreasing during anorthite crystallization should be based on variations within a given inclusion. There are differences in bulk composition among type B CAls, and a trend is not necessarily expected among data from different inclusions. (Compare the various model predictions on Fig. 8). Further, there should also be differences in $F_{\mathrm{p}}$ and $F_{\text {an }}$ among inclusions and even within a given inclusion, allowing for independent evolution of different pockets of liquid. All these variations would tend to produce scatter among data from different inclusions. Consequently, it is possible that the Ti$\mathrm{La}$ and $\mathrm{Ti}-\mathrm{Sr}$ trends are only apparent, leaving open the possibility that $\mathrm{Ti}$ is increasing in the liquid during the course of anorthite crystallization.

Considering all elements, the modeling can only be rated as mediocre overall, although the models appear relatively successful for the REEs and $\mathrm{Sr}$ (Figs. 5-7), especially if $25 \times \mathrm{CI}$ is assumed for the bulk abundances of these elements. Our use of the term modeling is consistent with contemporary practice; nevertheless, it should be emphasized that the input parameters to our calculations are almost entirely based on actual CAI data. The range of input parameters permitted by the observed data cannot account for major discrepancies between calculations and observations. Thus, the observed discrepancies represent primarily a lack of internal consis-

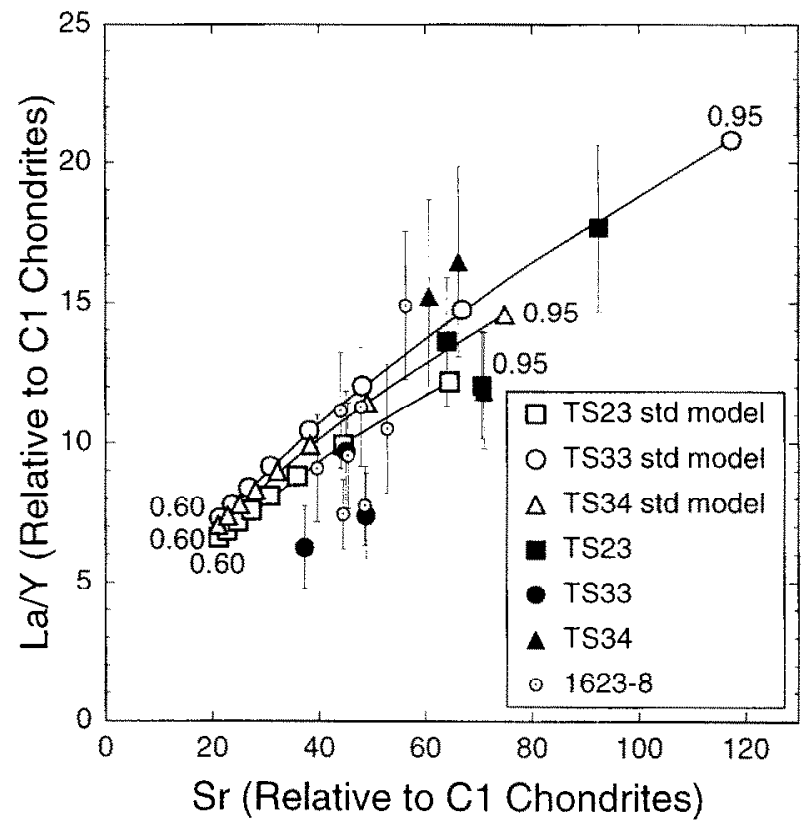

FiG. 7. Comparison of observed anorthite trends for La/ $\mathrm{Y}$ vs $\mathrm{Sr}$ with model predictions. Numbers on model curves refer to fraction crystallized $(F)$. Points on the model curves correspond to intervals of 0.05 in $F$ beginning with $F=F_{p}=0.6$ and ending at $F=0.95$. $\mathrm{La} / \mathrm{Y}$ depends primarily on the amount of pyroxene crystallized, so all models tend to lie on a similar trend. Except for TS33 the observed points are in the region of the calculated trend. 


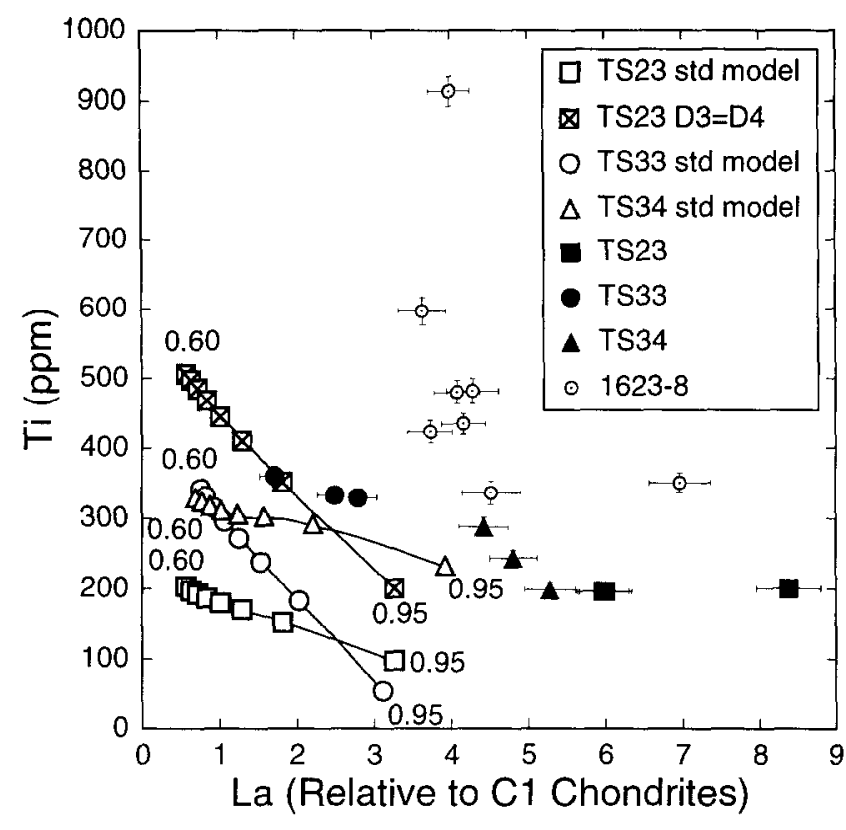

FIG. 8. Comparison of observed anorthite trends for Ti and La with model predictions. In addition to the standard models (D3 $=0$ ) the effect of assuming $D_{3}=D_{4}$ is shown for TS23. Points along model curves correspond to intervals of crystallization of 0.05 beginning at $F=F_{\mathrm{p}}=0.6$ and ending at $F=0.95$. The calculated inverse Ti-La trends correspond to a liquid dominated by pyroxene crystallization with Ti decreasing as crystallization proceeds. The observations suggest a similar trend; however, if anorthite crystallization occurred in the last $5 \%$, an increase of $\mathrm{Ti}$ in the liquid with increasing crystallization (and increasing La) would be expected.

tency in our observational inferences about the igneous history of CAIs, rather than the failure of a series of speculative assumptions. In this sense the discrepancies are more significant than the failure of yet another model. Subsolidus reequilibration of $\mathrm{Mg}$ could be the cause of one discrepancy, but even with this, relatively early anorthite crystallization would be indicated by $\mathrm{Ti}$ alone, contradicting the inferences from the REEs and $Y$ (compare Fig. 8 ). The best overall interpretation may be that anorthite crystallizes significantly later than pyroxene ( $F_{\text {an }} \geq 95 \%$ ). This conclusion probably can be more simply inferred from the fact that reverse-zoned rims on melilite are readily observable. If $F_{\mathrm{p}}$ and $F_{\text {an }}$ were close, only very thin bands of reverse zoning should occur. Finally, although speculative at this time, secondary alteration effects could be important.

The type B1 CAIs appear to have remarkable crystallization histories with different phases dominating different stages of the crystallization sequence: spinel for $0-15 \%$ crystallization, melilite for 15 to $60-75 \%$, pyroxene for $60-75$ to $95 \%$, and anorthite for the last $5 \%$. The very high concentrations of incompatible trace elements in some pyroxenes (SIMON et al., 1991) indicatc that pyroxenc crystallization also occurs in the last $5 \%$, but this does not preclude anorthite being the predominant crystallizing phase.

\section{Perovskite Partitioning}

\section{Effects of oxygen fugacity}

For the $\mathbf{R E F}+\mathrm{Y}\left(\mathbf{R}^{+3}\right)$ our perovskite $D$ values increase strongly with decreasing $f_{\mathrm{O}_{2}}$ probably due to the presence of trivalent $\mathrm{Ti}$ and the coupled substitution: $\mathrm{R}^{+3}+\mathrm{Ti}^{+3} \leftrightharpoons \mathrm{Ca}^{+2}$ $+\mathrm{Ti}^{+4}$ (see Results section and Table 5). The increase is a good example of how, because of coupled substitutions, $D$ values of elements with only one valence state can depend on $f_{\mathrm{O}_{2}}$. This effect is somewhat greater for the HREEs for unknown reasons. The $D$ values at low $f_{\mathrm{O}_{2}}$ are the most applicable for CAI conditions.

SMYTH (1989) proposes that Al substitution into perovskite occurs via creation of oxide vacancies and that the abundance of such vacancies should be enhanced at low oxygen fugacities. However, our measured $\mathrm{Al} D$ is lower at lower oxygen fugacity. The decrease in $\mathrm{Al} D$ might reflect competition from the $\mathrm{R}^{+3}+\mathrm{Ti}^{+3}$ mechanism at low $f_{\mathrm{O}_{2}}$.

\section{Comparison with previous work}

Figure 9 compares our REE $D$ patterns in perovskite with previous measurements by RINGWOOD (1975), NAGASAWA et al. (1980), and KENNEDY et al. (1993). Qualitatively, the patterns are similar; however, the spread in LREE $D$ values (factor of 5) is larger than that for the HREEs (factor of 3 ). There are no obvious analytical issues in this comparison, but experimental conditions differ greatly. KENNEDY et al. (1993) used a CAI composition with higher $\mathrm{Ca}$ and Ti than ours with crystals grown at $75^{\circ} \mathrm{C} / \mathrm{hr}$ over the range 1450 $1545^{\circ} \mathrm{C}$ at an $f_{\mathrm{O}_{2}}$ of $1.5 \mathrm{log}$ units below Fe-FeO. Their $D$ values for $\mathrm{La}$ and $\mathrm{Sm}$ are about 30\% higher than our low $f_{\mathrm{O}_{2}}$ values, but their $D$ for $\mathrm{Yb}$ is close to our low $f_{\mathrm{O}_{2}}$ data. The KenNeDY et al. (1993) $D$ for $\mathrm{Sr}$ is about a factor of 1.6 higher, and that for $\mathrm{Zr}$ a factor of 3 higher than ours. The experiments of NAGASAWA et al. (1980) are for a bulk composition of $32 \mathrm{wt} \% \mathrm{TiO}_{2}, 38 \% \mathrm{CaO}, 30 \% \mathrm{SiO}_{2}$, (nominally $\mathrm{Al}$-free). If REE substitution into perovskite occurs as (REE) $\mathrm{AlO}_{3}$, this can explain the lower $D$ values of NAGASAWA et al. (1980). The starting composition for the RINGWOOD (1975) experiments is not given, but a mixture of $\mathrm{CaIiO}_{3}$ and $\mathrm{Ca}-\mathrm{Al}$-rich pyroxene was used with crystals grown by cooling from $1500^{\circ}$ to $1350^{\circ} \mathrm{C}$. For ideal solid solution (compare BECKETT et al., 1990), the REE substitution re-

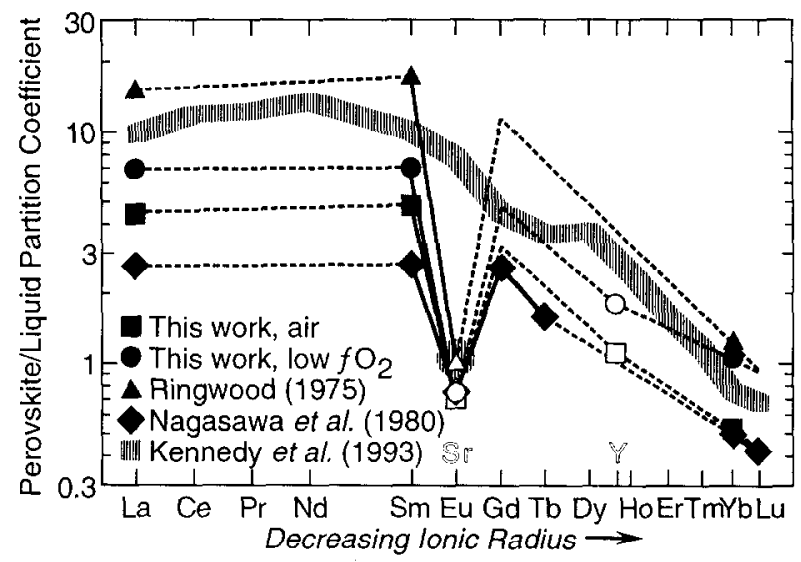

FIG. 9. Measured perovskite partition coefficients from this work for two different oxygen fugacities, compared with previous measurements by RINGWOOD (1975), NAGASAWA et al. (1980) and KENNEDY et al. (1993). The increase in REE partition coefficient with decreasing oxygen fugacity reflects the opening of a coupled substitution involving trivalent $\mathrm{Ti}$. 
action indicates that $D$ values should increase with $[\mathrm{Al} /(\mathrm{Ti}$ $\times \mathrm{Ca})]_{\text {liq }}$, but this ratio is roughly three times higher for our composition than that of RINGwOOD (1975). No information about oxygen fugacity is given by RINGWOOD (1975) but it is extremely unlikely that his conditions were much more reducing than our QPX-9 experiment. The QPX-9 perovskites are unusual, cross-shaped crystals, possibly indicative of disequilibrium growth, which could make our I a and Sm $D$ values low. However, disequilibrium partitioning would result in pronounced zoning for elements with $D$ values as large as those of the LREEs, but the QPX perovskites are remarkably homogeneous. Also, the change in $\mathrm{Al} D$ between QPX-8 and QPX-9 is in the wrong direction to be caused by a greater degree of disequilibrium partitioning in the QPX9 sample. Thus, there is no simple explanation why our $D$ values should be significantly lower than those of RINGWOOD (1975) or of KENNEDY et al. (1993). It may be that perovskite $D$ values increase strongly as temperature increases, or are very sensitive to liquid composition differences beyond that indicated by the substitution reaction.

\section{Comparison with perovskite in CAIS}

Perovskite is common in CAIs. An important application of our data is to aid in the distinction between igneous perovskites and those formed by high temperature gas-solid equilibria in the solar nebula. In the equilibrium condensation sequence (GROSSMAN, 1972), perovskite is regarded as the dominant host phase for REEs (GROSSMAN and LARIMER, 1974; KORNACKI and FEGLEY, 1986), although hibonite must also be considered (DAvis et al., 1982).

An igneous perovskite will tend to be imprinted by the uniform LREE ( $\mathrm{La}-\mathrm{Sm}$ ) enrichment of the $D$ pattern; however, in some cases the effect of perovskite on the REE pattern would be relatively subtle. For example, in an igneous spinelperovskite sample, all REEs would tend to be in perovskite, which on average would show the total rock pattern, assuming spinel had no REEs. However, spectacular REE zoning would be present in such perovskites if the sample formed by closed system fractional crystallization.

Solid-solid equilibration could ohscure a primary igneous or nebular origin. In particular, the equilibration of perovskite with clinopyroxene has the potential for significant REE fractionation, given the strong preference of clinopyroxene for HREEs over LREEs, the opposite of perovskite. A variety of REE patterns can be obtained, depending on the nature and relative abundances of the partitioning phases. Overall trace element distributions in compact type A inclusions show no evidence for solid-solid equilibration (DAVIS et al., 1990).

A specific model for a type A composition is illustrated in Fig. 10, adopting a simplified fractional crystallization history based on BECKETT (1986): Stage I: $15 \%$ spinel $+77 \%$ melilite crystallization (varying linearly with crystallization from $\AA \mathrm{k} 0$ to Åk35); Stage II: $0.7 \%$ perovskite $+7 \%$ melilite crystallization ( $\mathrm{k} k 35-\AA ̊ \mathrm{k} 40$ ).

Melilite $D$ values for REEs from Appendix Table B1 were used for $X_{\dot{A} k}>\AA \mathrm{k} 12$. Below this, the extrapolation to $\AA \mathrm{k} 0$ proposed by KUEHNER el al. (1989) was used. REE $D$ values in spinel were assumed to be zero. Based on KUEHNER et al. (1989), a constant value of 0.0015 for the melilite $D$ for $\mathrm{Zr}$ was used. For perovskite the QPX-9 $D_{\mathrm{c}}$ from Table 6 were used. For missing REEs, $D$ values were interpolated assuming a linear $\log D$ vs. ionic radius relation. A bulk composition of $17 \times \mathrm{CI}$ was assumed.

Prior to the appearance of perovskite, melilite crystallization produces a liquid which is slightly LREE-depleted (Fig. 10 ); nevertheless, the initial, core perovskite has a sizeable LREE enrichment. If there are CAI compositions which crystallize pyroxene before perovskite, the LREE enrichments in these cases would be even more enhanced than the core pattern shown in Fig. 10. With further crystallization, the liquid becomes progressively HREE-enriched, causing late perovskites (rim; Fig. 10) to have flat patterns and then become IIREE-enriched in the final $1 \%$ of crystallization. If pyroxene crystallizes after perovskite (A. El Goresy, pers. commun.), this would tend to produce flatter REE patterns in the liquid and in later-formed perovskite. Chondrite-normalized REE and $Y$ patterns from single analyses of perovskites from two Allende compact type A inclusions (A. Davis, unpub. data) are compatible with the model curves in Fig. 10. FAIIEY et al. (1987) report ion probe data for four different perovskite grains from a type A inclusion which exhibit flat REE patterns with about $1000 \times \mathrm{CI}$ enrichments. Comparison with Fig. 10 shows that, although a chance analysis of a latestage perovskite might yield an approximately flat pattern, ubiquitous flat patterns with $1000 \times \mathrm{CI}$ enrichments, such as those observed by FAHEY et al. (1987) are difficult to derive by fractional crystallization.

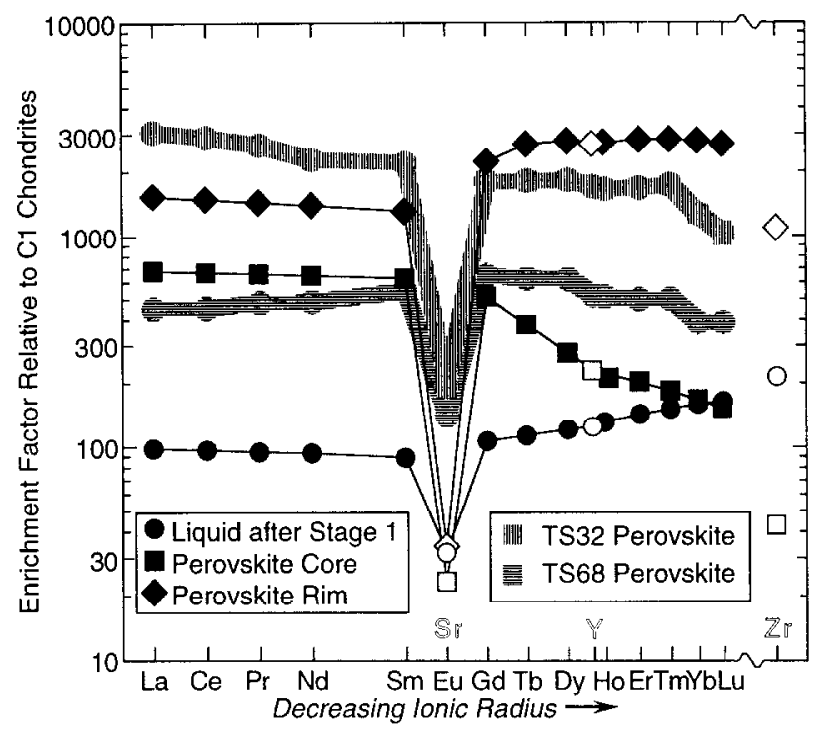

FIG. 10. Predicted REE patterns for perovskite in a simple crystallization model of a type A CAI composition based on BECKETT (1986), illustrating use of the REE to distinguish between igneous and nehular perovskites. Crystallization of $92 \%$ spinel and melilite (Stage 1) has created a slightly light REE-depleted liquid from which perovskites form. The last-formed perovskite (RIM in this figure refers to perovskite formed after $99 \%$ crystallization) can have patterns which are relatively flat, but the early formed material (CORE in this figure refers to the first perovskite at $92 \%$ crystallization ) should show a characteristic heavy REE depletion, reflecting the partition coefficient pattern, from which an igneous origin can be discerned. Perovskite analyses from two Allende compact type A inclusions (A. Davis, unpubl. data) have REE patterns qualitatively consistent with the model. 
If the total inclusion pattern contains volatility-derived structure, e.g., a group II REE pattern (MARTIN and MASON, 1974 ), close analysis is required to discern an igneous origin. For example, perovskites in the VSAD ( V-spinel, anorthite, diopside) part of CAI TS63F1 (LAUGHLIN et al., 1988) have a HREE pattern similar to Group II. It is unlikely that these perovskites are igneous because the observed $\mathrm{Tm} /$ (light REE) ratio is nearly chondritic.

Quantitative comparisons for VSAD require knowledge of the crystallization sequence for a hypothetical VSAD liquid. Nevertheless, assuming a group II initial REE pattern, a liquid highly enriched in the HREEs would be required at some stage in the crystallization to form pcrovskite with chondrite-normalized concentrations for Tm comparable to those of the LREEs. Except for perovskite itself, none of the phases present in VSAD are capable of producing such a liquid, and, as with the discussion for Fig. 10, HREE enrichments would be possible only for very late-stage perovskite rims.

Considerable data on $\mathrm{Y}$ and $\mathrm{Zr}$ in perovskite are available from KORNACKI and WOOD (1985), although $\mathrm{ZrO}_{2}$ inclusions (DAVIS, 1991) may have affected some analyses. A wide range in concentrations is observed, both above and below those for a nebular perovskite ( $\mathrm{Zr} / \mathrm{Ti}$ and $\mathrm{Y} / \mathrm{Ti}$ at $\mathrm{CI}$ chondrite levels; approximately $0.43 \% \quad \mathrm{ZrO}_{2}$ and $0.16 \% \quad \mathrm{Y}_{2} \mathrm{O}_{3}$, corresponding to CI-normalized abundances of around 1000 ). It is difficult for $\mathrm{Y}$ and $\mathrm{Zr}$ to reach concentrations above the nebular value by crystal-liquid fractionation from a melt with uniform enrichment of refractory elements. For the model used for Fig. 10,98.6\% crystallization must occur to achieve $\mathrm{Y}$ enrichments of $1000 \times \mathrm{CI}$, and a large number of perovskites with much lower $\mathrm{Y}$ contents would also be present. It is especially difficult for $\mathrm{Zr} / \mathrm{Y}$ to reach the $\mathrm{CI}$ ratio.

As $\mathrm{Zr}$ and $\mathrm{Y}$ can be super-refractory elements, even relative to $\mathrm{Ti}$, bulk $\mathrm{CAI}$ ratios of $\mathrm{Zr} / \mathrm{Ti}$ and $\mathrm{Y} / \mathrm{Ti}$ could be above $\mathrm{CI}$ values. For typical CAI refractory element enrichment factors of 10-20×CI, additional enhancements in bulk Y/Ti and $\mathrm{Zr} / \mathrm{Ti}$ to a factor of 5-10 above $\mathrm{CI}$ are required to produce nebular or higher $\mathrm{Y}$ and $\mathrm{Zr}$ concentrations in cores of igneous perovskites. Consequently, perovskite grains with greater than nebular $\mathrm{Zr}$ concentrations and $\mathrm{Zr} / \mathrm{Y}$ near chondritic are unlikely to be igneous, and these probably do represent super high temperature nebular material.

KORNACKI and WOOD (1985) proposed that CAIs containing perovskites which have low $\mathrm{ZrO}_{2}(<0.1 \%)$ and $\mathrm{Y}_{2} \mathrm{O}_{3}$ $(<0.05 \%)$ have bulk group II REE patterns, and many of the inclusions studied by KORNACKI and WOOD (1985) were independently known to have group II patterns. However, igneous perovskites would also fall into this composition range, and an origin for some of these perovskites by crystallization from a group I liquid cannot be ruled out without further information on the perovskites and coexisting phases.

Acknowledgments-We were aided by reviews from A. El Goresy and two anonymous reviewers. This research was supported by NASA grants NAG 9-54 and NAGW-3340 (Grossman), NAG 9-111 and NAGW-3384 (Davis), NAG 9-94 and NAGW-1852 (Burnett) and NAG 9-51 and NAGW-3345 (R. N. Clayton).

Fditorial handling: C. Koeberl

\section{REFERENCES}

BECKETT J. R. ( 1986) The origin of Ca-Al-rich inclusions from carbonaceous chondrites: an experimental study. $\mathrm{Ph} . \mathrm{D}$. dissertation, Univ. Chicago.

Beckett J. R., Spivack A. J., Hutcheon l. D., Wasserburg G. J., and Stolper E. M. (1990) Crystal chemical effects on the partitioning of trace elements between minerals and melt: An experimental study of melilite with applications to refractory inclusions from carbonaceous chondrites. Geochim. Cosmochim. Acta 54, $1755-1774$.

Benjamin T. M., Heuser W. R., Burnett D. S., and Seitz M. G. (1980) Actinide crystal-liquid partitioning for clinopyroxene and $\mathrm{Ca}_{3}\left(\mathrm{PO}_{4}\right)_{2}$. Geochim. Cosmochim. Acta 44, 1251-1264.

BLUNDY J. D. and WoOd B. J. (1991) Crystal-chemical controls on the partitioning of $\mathrm{Sr}$ and $\mathrm{Ba}$ between plagioclase feldspar, silicate melts, and hydrothermal solutions. Geochim. Cosmochim. Acta 55, 193-209.

BuRNetT D. S., Johnson M. L., and WoOlum D. S. (1990) Relict grains in CAIs revisited. Meteoritics 25, 353 (abstr.).

DAVIS A. M. (1991) Ultrarefractory inclusions and the nature of the group II REE fractionation. Meteoritics 26, 330 (abstr.).

Davis A. M., TANaKa T., Grossman L., LeE T., and WasserburG G. J. (1982) Chemical composition of HAL, an isotopically-unusual Allende inclusion. Geochim. Cosmochim. Acta 46, 16271651.

Davis A. M., Simon S. B., and Grossman L. (1990) Trace element distributions in Allende compact type A inclusions. Meteoritics 25, 356 (abstr.).

Davis A. M., MaCPherson G. J., Claytun R. N., Mayeda T. K., Sylvester P. J., Grossman L., Hinton R. W., and Laughlin J. R. (1991) Melt solidification and late-stage evaporation in the evolution of a FUN inclusion from the Vigarano C $3 \mathrm{~V}$ chondrite. Geochim. Cosmochim. Acta 55, 621-638.

Davis A. M., Simon S. B., and Grossman L. (1992) Melilite composition trends during crystallization of Allende Type B1 refractory inclusion melts. Lunar Planet. Sci. XXIII, 281-282 (abstr.).

DowTY E. (1976) Crystal structure and crystal growth II: Sector zoning in minerals. Amer. Mineral. 61, 460-469.

DRAKE M. J. and WEILL D. F. (1972) New rare earth element standards for electron microprobe analysis. Chem. Geol. 10, 179-181.

DRAKE M. J. and WEILL D. F. (1975) The partition of $\mathrm{Sr}, \mathrm{Ba}, \mathrm{Ca}, \mathrm{Y}, \mathrm{Eu}^{2+}, \mathrm{Eu}^{3+}$, and other $\mathrm{REE}$ between plagioclase feldspar and magmatic silicate liquid: An experimental study. Geochim. Cosmochim. Acta 39, 689-712.

Fahey A. J., ZinNer E. K., Crozaz G., and KornaCKI A. S. (1987) Microdistribution of $\mathrm{Mg}$ isotopes and REE abundances in a type A calcium-aluminum-rich inclusion from Efremovka. Geochim. Cosmochim. Acta 51, 3215-3229.

Grossman L. (1972) Condensation in the primitive solar nebula. Geochim. Cosmochim. Acta 36, 597-619.

GrossmaN L. (1980) Refractory inclusions in the Allende meteorite. Ann. Rev. Earth Planet. Sci. 8, 559-608.

GROSSMAN L. and LARIMER J. W. (1974) Early chemical history of the solar system. Rev. Geophys. Space Phys. 12, 71-102.

Hinton R. W., Davis A. M., SCATENa-WaChel D. E., Grossman L., and DRAuS R. J. (1988) A chemical and isotopic study of hibonite-rich refractory inclusions in primitive meteorites. Geochim. Cosmochim. Acta 52, 2573-2598.

hutcheon 1. D., Steele 1. M., Smith J. V., and Clayton R. N. (1978) Ion microprobe, electron microprobe and cathodoluminescence data for Allende inclusions with emphasis on plagioclase chemistry. Proc. 9th Lunar Planet. Sci. Conf., 1345-1368.

Johnson M. L., BuRnetT D. S., and WoOLUM D. S. (1988) Relict refractory element rich phases in Type B CAI. Meteoritics 23, 276 (abstr.).

JONES J. H. and BURNETT D. S. ( 1987) Experimental geochemistry of $\mathrm{Pu}$ and $\mathrm{Sm}$ and the thermodynamics of trace element partitioning. Geochim. Cosmochim. Acta 51, 769-782.

KFNNFDY A. K., HITTCHFON I. D., and WASSFRBI IRG G. I. (1991) Trace element distributions in compact Type A CAI in Allende and Leoville. Evidence for relict perovskite. Lunar Planet. Sci. XXII, 709-710 (abstr.). 
KFnNfDy A. K., Lofgren G. E., and WAsserbuRg G. J. ( 1993) An experimental study of trace element partitioning between perovskite, hibonite, and melt. Lunar Planet. Sci. XXIV, 793-794 (abstr.).

KORNACKI A. S. and FegLEY B. (1986) The abundance and relative volatility of refractory trace elements in Allende $\mathrm{Ca}, \mathrm{Al}-$-rich inclusions: implications for chemical and physical processes in the solar nebula. Earth Planet. Sci. Lett. 79, 217-234.

KORNACKJ A. S. and WoOD J. A. (1985) The identification of Group II inclusions in carbonaceous chondrites by electron probe microanalysis of perovskite. Earth Planet. Sci. Lett. 72, 74-86.

KuehNER S. M., LAUGhLin J. R., Grossman L., JohnSON M. L., and BURNETT D. S. (1989) Determination of trace element mineral/liquid partition coefficients in melilite and diopside by ion and electron microprobe techniques. Geochim. Cosmochim. Acta 53, 3115-3130.

Laughlin J. R., Davis A. M., Kuehner S. M., and Grossman L. (1988) Rare earth elements in a compound Group II Allende inclusion. Lunar Planet. Sci. XIX, 661-662 (abstr.).

LoNGH J., WALKeR D., and HAYS J. F. (1976) Fe and Mg in plagioclase. Proc. 7th Lunar Sci. Conf., 1281-1300.

MACPherson G. J. and DAvis A. M. (1993) A petrologic and ion microprobe study of a Vigarano Type B refractory inclusion: Evolution hy multiple stages of alteration and melting. Geochim. Cosmochim. Acta 57, 231-243.

MacPherson G. J., Paque J. M., Stolper E., and Grossman L. (1984) The origin and significance of reverse zoning in melilite from Allende Type B inclusions. J. Geol. 92, 289-305.

MARTIN P. M. and MASON B. (1974) Major and trace elements in the Allende meteorite. Nature 249, 333-334.

MCKAY G. A. (1982) Partitioning of REE between olivine, plagioclase, and synthetic basaltic melts: Implications for the origin of lunar anorthosites. Lunar Planet. Sci. XIII, 493-494 (abstr.).

MORSE S. A. ( 1992) Partitioning of Sr between plagioclase and melt: A comment. Geochim. Cosmochim. Acta 56, 1735-1737.

MURRELL. M. T. and BURNETT D. S. (1987) Actinide chemistry in Allende Ca-Al-rich inclusions. Geochim. Cosmochim. Acta 51, 985-999.

NAGASAWA H., SChreiber H. D., and MorRis R. V. (1980) Experimental mineral/liquid $\mathrm{Ds}$ of $\mathrm{REE}, \mathrm{Si}$, and $\mathrm{Sr}$ for perovskite, spinel, and melilite. Earth Planet. Sci. Lett. 46, 43I-437.

PHINNEY W. C. (1991) Lunar anorthosites, their equilibrium melts and the bulk Moon. Proc. 21st Lunar Planet. Sci. Conf., 29-49.

Phinney W. C. and Morrison D. A. (1990) Partition coefficients for calcic plagioclase: Implications for Archean anorthosites. Geochim. Cosmochim. Acta 54, 1639-1654.

Phinney W. C., Lindstrom D. J., MitTlefehldt D. W., and MARTINEZ R. R. (1993) Post-igneous redistribution of components in eucrites. Lunar Planet. Sci. XXIV, 1137-1138 (abstr.).

Rinciwoon A. F. ( 1975) Some aspects of the minor element chemistry of lunar mare basalts. The Moon 12, 127-157.

RuZicK A A. and BoYNTON W. V. (1993) The anatomy and bulk composition of CAI rims in the Vigarano ( $\mathrm{CV} 3$ ) chondritc. $\mathrm{Me}$ teoritics 28, 426 (abstr.).

SHANNON R. D. (1976) Revised effective ionic radii and systematic studies of interatomic distances in halides and chalcogenides. Acta Cryst. A32, 751-767.

SIMON S. B. and GROSSMAN L. (1991) Profiles of $\mathrm{Ti}^{3+} / \mathrm{Ti}^{\text {tot }}$ in zoned fassaite in Allende refractory inclusions. Meteoritics 26, 395 (abstr.).

Simon S. B., GRossman L., and Davis A. M. (1991) Fassaite composition trends during crystallization of Allende Type B refractory inclusion melts. Geochim. Cosmochim. Acta 55, 2635-2656.

SimON S. B., Davis A. M., and GrosSMAN L. (1992) Evidence for changes in redox state during crystallization of Allende type B1 inclusions. Meteoritics 27, 289-290 (abstr.).

SMiTh J. V. and Brown W. L. (1988) Feldspar Minerals. Vol. 1. Springer-Verlag.

SMYTH D. M. (1989) Defect equilibria in perovskite oxides. In Chapman Conference on Perovskite Structures, pp. 99-103. AGU Monogr.

STOLPER E. M. (1982) Crystallization sequences of Ca-Al-rich inclusions from Allende: an experimental study. Geochim. Cosmochim. Acta 46, 2159-2180.
STOI.PFR E. M. and PAQIJF. J. M. (1986) Crystallization sequences of $\mathrm{Ca}-\mathrm{Al}$-rich inclusions from Allende: The effects of cooling rate and maximum temperature. Geochim. Cosmochim. Acta 50, 17851806.

WEILL D. F. and MCKAY G. A. (1975) The partitioning of $\mathrm{Mg}, \mathrm{Fe}, \mathrm{Sr}, \mathrm{Ce}, \mathrm{Sm}, \mathrm{Eu}$, and $\mathrm{Yb}$ in lunar igneous systems and a possible origin for KREEP by cquilibrium partial melting. Proc. 6 th Lunar Sci. Conf., 1143-1158.

WOOLUM D. S., JOHNSON M. L., BURNetT D. S., and SUTton S. (1988) Refractory lithophile partitioning in type B CAI materials. Lunar Planet. Sci. XIX, 1294-1295 (abstr.).

\section{APPENDIX A: PREDICTION OF MAGNESIUM AND TITANIUM CONTENTS IN ANORTHITE}

We divide the crystallization history into three stages: (1) spinel alone; (2) melilite and spinel to $F=F_{\mathrm{p}}$, where $F$ is the fraction crystallized; and (3) crystallization of melilite and pyroxene for $F$ $>F_{\mathrm{p}}$. Anorthite crystallizes at $F=F_{\text {an }}$, with the only condition being that $F_{\mathrm{an}}>F_{\mathrm{p}}$. For the calculation of $\mathrm{Mg}$ and Ti contents in anorthite, detailed treatment of stages 1 and 2 is not required. Given $\mathrm{MgO}$ and $\mathrm{TiO}_{2}$ in pyroxene as a function of $F$, the only other major required parameters are the $\mathrm{MgO}$ and $\mathrm{TiO}_{2}$ concentrations in the liquid at the end of stage 2. For the STOLPER (1982) crystallization sequence, spinel appears to stop crystallizing at or before $F=50 \%$, probably dissolving at lower temperatures (STOLPER, 1982). For fractional crystallization and $F>50 \%$ it is reasonable to assume that spinel crystallization is complete but that dissolution can be ignored. Thus, for stage 3, spinel can be ignored, and the $\mathrm{Mg}$ material balance is:

$$
\mathrm{MgO}_{\mathrm{liq}}(2) *\left(1-F_{\mathrm{p}}\right)=\langle\AA \mathrm{k} \mathrm{k}\rangle_{3} * 0.148 * f_{\text {mel }}(3)+\langle\mathrm{MgO}\rangle_{\mathrm{p}} * f_{\mathrm{p}},(1)
$$

where $\mathrm{MgO}_{\text {liq }}(2)$ is the liquid concentration at the end of stage 2, ( 1 $\left.-F_{\mathrm{D}}\right)$ is the fraction of liquid left after stage $2(40 \%$ for the standard model), $\langle\AA \hat{k}\rangle_{3}$ is the mean mole fraction of Åk in the melilite for stage $3, f_{\text {mel }}(3)$ is the amount of the melilite crystallized in stage 3 , $\langle\mathrm{MgO}\rangle_{\mathrm{p}}$ is the average $\mathrm{MgO}$ in pyroxene, and $f_{\mathrm{p}}$ is the modal abundance of pyroxene (e.g., $20 \%$ for $\mathrm{TS}_{23}$ ). All observed $\mathrm{TiO}_{2}$ is in pyroxene, thus:

$$
\mathrm{TiO}_{2, \operatorname{lin}}(2) *\left(1-F_{\Gamma}\right)=\left\langle\mathrm{TiO}_{7}\right\rangle_{\mathrm{p}} * f_{\mathbf{p}},
$$

where $\mathrm{TiO}_{2 \text {.liq }}(2)$ is the $\mathrm{TiO}_{2}$ concentration in the liquid at the end of stage 2 and $\left\langle\mathrm{TiO}_{2}\right\rangle_{\mathrm{p}}$ is the average pyroxene $\mathrm{TiO}_{2}$ concentration.

Equations 1 and 2 are effectively boundary conditions which couple the initial stage 3 liquid concentrations to the assumed model for pyroxene and melilite compositions in stage 3 as a function of degree of crystallization $(F)$. The pyroxene composition model is discussed below. In addition to determining the $\mathrm{TiO}_{2}$ and $\mathrm{MgO}$ concentrations in pyroxene as a function of $F$, the pyroxene model also determines the required average $\mathrm{MgO}$ and $\mathrm{TiO}_{2}$ in the crystalline phases for Eqn. 1 and 2, which then can be solved for the initial $\mathrm{MgO}$ and $\mathrm{TiO}_{2}$ contents in the liquid for stage 3.

The description of late-stage melilite crystallization is not critical, especially when the amount of melilite in stage 3 is small. Stage 3 melilite corresponds to the reversed zoning region (MACPHERSON et al., 1984). For TS23 we adopt the trend given by MACPHERSON et al. (1984, Fig. lb) in which, at the onset of pyroxene crystallization (i.e., when $F=F_{\mathrm{p}}$ ), the melilite is $\AA \mathrm{k} 70$, but drops to $\AA \mathrm{k} 52$ for very late melilite. We assume that $\AA \mathrm{k} 52$ corresponds to $95 \%$ crystallization and that $\AA$ k varies linearly with $F$ between $F_{\mathrm{p}}$ and $95 \%$. These assumptions are uncertain but, as noted above, final results are insensitive to them. For example, calculations with constant $\AA \mathrm{k}=\langle\AA \mathrm{k}\rangle_{3}$ in stage 3 show negligible differences from the standard model. Thus, it is sufficiently accurate to adopt the dependence of $\AA$ k on $F$ from TS23 for TS34 and TS33. Reversely zoned melilite is observed in TS23 and TS34, but not in TS33, although quantitative data are only available for TS23. For TS34, $\langle\AA \mathrm{k}\rangle_{3}$ was scaled by the ratios of the average core Åk for TS34 and TS23 (BECKETT, 1986). For TS33, $\langle\AA \mathrm{k}\rangle_{3}$ was taken to be 0.6 , but a separate model with 0.5 showed insignificant differences.

Actual calculation of the $\mathrm{TiO}_{2}$ and $\mathrm{MgO}$ concentrations in the liquid as a function of $F$ during stage 3 was done numerically by 
material balance. Beginning with the initial $\mathrm{MgO}$ and $\mathrm{TiO}_{2}$ concentrations in the liquid from Eqns. 1 and 2, a $1 \%$ increment of crystallization was assumed, and the amounts of $\mathrm{MgO}$ and $\mathrm{TiO}_{2}$ removed by pyroxene and melilite were calculated from the models for crystal compositions as a function of $F$, and then were subtracted from the liquid, producing a new liquid composition. This calculation was repeated successively from $F=F_{\mathrm{p}}$ to $F=95 \%$ or $F=F_{\text {an }}$, with $F$ $=95 \%$ corresponding to the standard model. For $F>F_{\text {an }}$ the relative amount of anorthite determined from the modal proportions was removed from the mass of liquid.

Using the crystallization models described above and our measured $D$ values (Table 4 ), trace element contents in anorthite can be obtained from the calculated stage 3 liquid compositions as a function of the amount of crystallization $(F)$. Modeling of the last few percent of crystallization is uncertain, and we have not attempted to model beyond $95 \%$ crystallization.

Required modes and mineral compositions from BECKETT (1986) or SIMON et al. (1991) are summarized in Table A1. The amount of crystallization at which pyroxene appears, $F_{\mathrm{p}}$, is not a completely free parameter but is constrained by the modes for pyroxene and anorthite. For example, for TS23 with $20 \%$ pyroxene and $3 \%$ anorthite by weight, the absolute maximum value for $F_{\mathrm{p}}$ is $77 \%$ (Table Al). Some melilite continues to crystallize in stage 3 (MACPHERSON et al., 1984), so adopted values of $F_{\mathrm{p}}$ for modeling are less than these absolute maximum values. SIMON et al. (1991) infer $F_{\mathrm{p}}=75 \%, 69 \%$, and $59 \%$ for TS23, TS34, and TS33, respectively. For equilibrium crystallization of the CAI composition used by STOLPER (1982), $F_{\mathrm{p}}$ is $60 \%$. If the suppression of anorthite does not affect the appearance temperature of pyroxene, $F_{\mathrm{p}}$ could be less than $60 \%$; however, a finite cooling rate will also suppress pyroxcne nuclcation. Thus, $F_{\mathrm{p}}=60 \%$ is a plausible lower bound for TS23 and TS34, and is approximately the inferred value for TS33 by SIMON et al. (1991). We adopt $F_{\mathrm{p}}$ $=60 \%$ for calculation of a standard model for all inclusions. Calculations adopting higher values of $F_{\mathrm{p}}$ do not produce significantly different results. Because the amounts of anorthite are small (Table A1), the liquid composition in stage 3 is initially insensitive to whether or not anorthite has crystallized. However, for $F>80 \%$ the effect of uncrystallized anorthite, as inert mass in the liquid, becomes noticeable. In the standard models the modal abundance of anorthite is included, but anorthite is assumed not to crystallize.

The required variation of pyroxene composition with $F$ cannot be obtained from first principles or from experimental studies to date; however, in principle it is derivable from observed CAI pyroxene zoning patterns if we assume that the observations include the true crystal core (i.e., the first-formed pyroxene), and if uniform crystal growth can be assumed. With these assumptions, $f_{\mathrm{p}}(r)=(r / R)^{1 / 3}$, where $f_{\mathrm{p}}$ is the fraction of pyroxene crystallized and $r$ is the position along an electron microprobe traverse in a direction where the distance from the crystal center to edge is $R$. We used the pyroxene zoning profiles for TS23 and TS34 given by SiMON et al. (1991, Fig. 5) along with two additional profiles of TS23, three profiles of TS33, and two additional profiles of TS34. For calculation, the data for each inclusion were fit to a third order polynomial in $(r / R)$. The zoning profiles thus give $\mathrm{Ti}$ and $\mathrm{MgO}$ contents in pyroxene as a function of $f_{\mathrm{p}}$. The relationship between $f_{\mathrm{p}}$ and $F$ is defined by the crystallization model and the adopted set of modal abundances. For example, the $F_{\mathrm{p}}=60$ standard model for TS23 assumes $f_{p}=0$ at $F=60 \%$, and uniform crystallization of melilite and pyroxene in $0.838 / 1$ proportions between $F=60$ and $F=95 \%$. This melilite/pyroxene ratio follows from the choice of $F_{\mathrm{p}}$ and the modes. Thus, combining the model and the zoning data gives $\mathrm{MgO}$ in pyroxene as a function of $F$.

Titanium is a multivalent element in CAIs, and our measured anorthite $D$ values apply only to $\mathrm{Ti}^{+4}$. CAI pyroxenes contain comparable amounts of +3 and +4 Ti (SIMON et al., 1991). Based on the observed steep drop-off of $D$ with decreasing ionic radius for the trivalent REE, we assume that the $\mathrm{Ti}^{+3}$ partition coefficient $\left(D_{3}\right)$ in anorthite is zero for the standard model, as the ionic radius of $\mathrm{Ti}^{+3}$ is smaller than $\mathrm{Lu}^{+3}$ (SHANNON, 1976). We have also considered models for which $D_{3}=D_{4}$. In the standard model we use the $\mathrm{TiO}_{2}$ zoning data (which are calculated separately from $\mathrm{Ti}_{2} \mathrm{O}_{3}$ ) to give $\mathrm{TiO}_{2}$ in pyroxene as a function of $F$. Using the $\mathrm{TiO}_{2}$ directly observed in pyroxene removes the need to deal explicitly with the issue of $\mathrm{Ti}$
Table A1. Parameters for models of anorthite crystiallization in type B1 CAIs.

\begin{tabular}{|c|c|c|c|}
\hline & TS23 & TS33 & TS34 \\
\hline \multicolumn{4}{|l|}{ Modes (wt\%) } \\
\hline pyroxene & 20.4 & 32.8 & 25.0 \\
\hline melilite & 66.0 & 51.1 & 64.0 \\
\hline spinel & 11.1 & 12.0 & 10.3 \\
\hline anorthite & 2.5 & 4.1 & 0.7 \\
\hline$<\AA ̊ \mathrm{k}>_{3}(\%)^{*}$ & 62 & 60 & 56 \\
\hline$\langle\mathrm{MgO}\rangle_{\mathrm{px}}(\mathrm{wt} \%)^{\dagger}$ & 10.07 & 9.65 & 9.73 \\
\hline$\left\langle\mathrm{TiO}_{2}\right\rangle_{\mathrm{px}}(\mathrm{wt} \%)^{\dagger}$ & 2.30 & 2.40 & 2.61 \\
\hline$<T i>_{p x}(w t \%)^{\dagger}$ & 3.43 & 4.22 & 4.37 \\
\hline $\mathrm{MgO}_{\text {std }}(\mathrm{wt} \%)^{\ddagger}$ & 8.99 & 8.60 & 9.13 \\
\hline $\mathrm{TiO}_{2 \text { std }}(\mathrm{wt} \%)^{\ddagger}$ & 1.17 & 1.97 & 1.63 \\
\hline $\mathrm{Ti}$ std $(w t \%)^{\ddagger}$ & 1.75 & 3.46 & 2.73 \\
\hline $\mathrm{MgO}_{\mathrm{F}_{\mathrm{p}}}(\mathrm{wt} \%)^{\S}$ & 8.97 & 8.61 & 9.29 \\
\hline $\mathrm{TiO}_{2} \mathrm{~F}_{\mathrm{p}}(\mathrm{wt} \%)^{\S}$ & 1.84 & 1.92 & 2.08 \\
\hline $\mathrm{Ti}_{\mathrm{F}}\left({ }_{\mathrm{w}} \mathrm{t} \%\right)^{\S}$ & 2.75 & 3.37 & 3.49 \\
\hline $\mathrm{Alk}_{\min }(\%)^{\mathrm{d}}$ & 5 & 11 & 8 \\
\hline Ák $\mathrm{F}_{\mathrm{p}}(\%)^{\infty}$ & 70 & 68 & 64 \\
\hline $\operatorname{Max} F_{g}(\%)^{4}$ & 77.1 & 63.1 & 74.3 \\
\hline $\mathrm{F}_{\mathrm{p}}(\%)^{\gamma}$ & 74.5 & 58.9 & 69.1 \\
\hline
\end{tabular}

*average melilite composition in stage 3 (see text). $\dagger_{\text {average } \mathrm{MgO}, \mathrm{TiO}_{2} \text { and total titanium as }}$ $\mathrm{Ti}$ in pyroxene from integration of cubic fit to 3 profiles for each inclusion vs. radius fraction: data from SIMON et al. (1991) and unpublished data. ¥liquid composition at the beginning of stage 3 , using $F_{p}=60 \%$. \$liquid composition at the heginning of stage 3 , using $F_{p}$ values below. Composition of initial melilite. ${ }^{\infty}$ Melilite composition at $\mathrm{F}_{\mathrm{p}}$. TBECKETT (1986). ^SIMON et al. (1991).

valence state equilibration during crystallization; however, the implicit assumption behind this approach is that the $\mathrm{TiO}_{2} / \mathrm{Ti}_{2} \mathrm{O}_{3}$ observed in pyroxene is that present when pyroxene crystallization began. This assumption could be wrong. A better description of observations (Fig. 3 ) would require an increase in this ratio at high $F$, but this is opposite to inferences from detailed analysis of pyroxene zoning patterns ( $\mathrm{S}$ MON and GROSSMAN, 1991; SiMON et al., 1992). The choice of equal $D$ values for the $D_{3}=D_{4}$ model is arbitrary, although plausible. An advantage of this choice is that the model can be calculated reliably using measured pyroxene zoning profiles for total $\mathrm{Ti}$ (as opposed to $\mathrm{TiO}_{2}$ separately from $\mathrm{Ti}_{2} \mathrm{O}_{3}$ in the standard model). Above, we used the REE $D$ pattern for anorthite to argue that $D_{3}$ might be very small. This will be valid if $\mathrm{Ti}^{+3}$ substitutes into the Ca site; however, if $\mathrm{Ti}^{+3}$ can substitute into the tetrahedral site, the $D_{3}=D_{4}$ model is plausible.

Many alternatives to the standard model (Fig. 3 ) have been tested. It is unlikely that reasonable variation of the parameters given in Table A1 would produce major differences. Specifically, calculations in which $F_{\mathrm{p}}$ was varied or in which the shape of the $\mathrm{MgO}$ and $\mathrm{TiO}_{2}$ pyroxene zoning patterns were changed did not produce improved descriptions of the $\mathrm{Mg}$ and $\mathrm{Ti}$ contents in anorthite from those shown on Fig. 3.

\section{APPENDIX B: REE, YTTKIUM, STRONTIUM MODELING}

Early crystallization of melilite produces some REE fractionation; thus, unlike the situation for $\mathrm{Mg}$ and $\mathrm{Ti}$ above, explicit assumptions 
are required about spinel and melilite crystallization (stages 1, 2, Appendix A) prior to pyroxene nucleation. Final results for the REEs are insensitive to how stages 1 and 2 are modeled; $\mathrm{Sr}$ is more sensitive. For a standard model we modified the results of BECKETT et al. (1990) to (1) relate melilite composition and fraction crystallized and (2) define the trend of melilite $D$ values for REEs with the amount of crystallization $(F)$. BECKETT et al. (1990) show that melilite $D$ values for REEs are controlled by crystal chemistry. We adopt a simplified version of their results, taking $D(\mathrm{mel})=\mathrm{K}\left(X_{\mathrm{Ge}} / X_{\dot{\mathrm{Ak}}}\right)$, where $X_{\mathrm{Gc}}$ and $X_{\dot{\mathrm{A} k}}$ are the gehlenite and åkermanite mole fractions. Adopted values of $K$ are tabulated in Table B1. The $D$ values at low $\AA \mathrm{k}$ are most important; consequently values of $\mathrm{K}$ were chosen to match the $\mathrm{La}, \mathrm{Sm}, \mathrm{Yb}, \mathrm{Y}$, and $\mathrm{Sr} D$ values of KUEHNER et al. (1989) at $\AA$ k 12 . Values for the other REEs were obtained by interpolation, assuming a linear $\log D$ vs. ionic radius relation using ionic radii from SHANNON (1976). The BECKETT et al. (1990) relation between amount crystallized $(F)$ and melilite composition prior to pyroxene crystallization was generalized: $\AA \mathrm{k}(F)=A /(B+F)$, where the parameters $A$ and $B$ were calculated separately for inclusions TS23, TS33, and TS34 by assuming that the lowest observed Åk content in each inclusion (Table A1) corresponded to the first-formed melilite (beginning of stage 2 ) and by adopting the melilite composition at $F=F_{\mathrm{p}}$ used for the $\mathrm{Mg}$ and Ti modeling (Table Al). For stage 3 ( $F$ $\left.>F_{y}\right), D$ values for anorthite and pyroxene have been taken as constant (Table B1). The pyroxene $D$ values are based on a parabolic fit to the early $D$ values of SIMON et al. (1991) as a function of ionic radius. The ion probe data from Table 4 were used to interpolate a complete set of anorthite $D$ values, assuming a linear relationship between $\log D$ and ionic radius.

One half of the spinel (Table A1) was assumed to crystallize before melilite, followed in stage 2 by crystallization of the remaining spinel with melilite in proportions set by the modal abundances (Table A1) and by the choice of $F_{\mathrm{p}}$. Subsequent to pyroxene crystallization, the same liquid evolution models were used for stage 3 as for $\mathrm{Mg}$ and Ti (Table A1). With these assumptions, the REE and Sr concentrations in the liquid prior to pyroxene appearance can be calculated. As for the Mg-Ti calculations above, the standard model assumes that anorthite does not nucleate (i.e., the amount of crystallization that has occurred prior to anorthite nucleation, $F_{\text {an }}$, is greater than 95\%). For the type B CAIs in Table Al the modal abundance of
Table B1. Adopted partition coefficients for REE-Y-Sr modeling.

\begin{tabular}{llll}
\hline & $\mathrm{K}_{\text {mel }}{ }^{*}$ & $\mathrm{D}_{\text {fas }}$ & $\mathrm{D}_{\mathrm{an}}$ \\
\hline $\mathrm{Sr}^{+2}$ & 0.900 & 0.100 & 1.00 \\
$\mathrm{Y}^{+3}$ & 0.0600 & 0.781 & 0.00299 \\
$\mathrm{La}^{+3}$ & 0.0873 & 0.218 & 0.0236 \\
$\mathrm{Ce}^{+3}$ & 0.0895 & 0.337 & 0.0185 \\
$\mathrm{Pr}^{+3}$ & 0.0917 & 0.442 & 0.0145 \\
$\mathrm{Nd}^{+3}$ & 0.0940 & 0.533 & 0.0113 \\
$\mathrm{Sm}^{+3}$ & 0.0982 & 0.659 & 0.00737 \\
$\mathrm{Eu}^{+3}$ & 0.0882 & 0.700 & 0.00606 \\
$\mathrm{Gd}^{+3}$ & 0.0793 & 0.733 & 0.00499 \\
$\mathrm{~Tb}^{+3}$ & 0.0713 & 0.758 & 0.00410 \\
$\mathrm{Dy}^{+3}$ & 0.0641 & 0.775 & 0.00337 \\
$\mathrm{Ho}+3$ & 0.0561 & 0.783 & 0.00276 \\
$\mathrm{Er}^{+3}$ & 0.0468 & 0.785 & 0.00221 \\
$\mathrm{Tm}^{+3}$ & 0.0396 & 0.781 & 0.00180 \\
$\mathrm{Yb}^{+3}$ & 0.0341 & 0.774 & 0.00150 \\
$\mathrm{Lu}^{+3}$ & 0.0298 & 0.764 & 0.00128 \\
\hline \multicolumn{4}{l}{${ }^{*} \mathrm{D}_{\text {mel }}=\mathrm{K}_{\text {mel }} \frac{\mathrm{X}_{\mathrm{Gc}}}{\mathrm{X}_{\AA \mathrm{k}}}$, where $\mathrm{X}_{\mathrm{Ge}}=$ gehlen- }
\end{tabular}

ite mole fraction and $\mathrm{X} \AA \mathrm{A}=$ åkermanite mole fraction.

anorthite is small, thus its crystallization has little effect on the evolution of the trace element composition of the liquid, even for a moderately compatible element such as $\mathrm{Sr}$. The abundance of anorthite is $12 \%$, and $F_{\text {an }}=37 \%$ for the STOLPER (1982) model.

CI-normalized abundances were calculated assuming that bulk type B CAIs have uniform enrichment of refractory lithophile elements at $17 \times \mathrm{CI}$. 